\title{
Validation of Semi-empirical Models for the Prediction of Swelling Stress for Compacted Unsaturated Expansive Soils
}

\author{
Aneke Frank Ikechukwu ${ }^{1, *}$, Nkwonta Onyeka ${ }^{2}$ \\ ${ }^{1}$ College of Agriculture, Engineering and Science Howard College Campus, University of KwaZulu-Natal, Durban 4004, South Africa \\ ${ }^{2}$ Department of Civil Engineering, Mangosuthu University of Technology, PO Box 12363, Durban 4026, South Africa
}

Received April 6, 2021; Revised May 31, 2021; Accepted June 15, 2021

\section{Cite This Paper in the following Citation Styles}

(a): [1] Aneke Frank Ikechukwu, Nkwonta Onyeka, "Validation of Semi-empirical Models for the Prediction of Swelling Stress for Compacted Unsaturated Expansive Soils," Civil Engineering and Architecture, Vol. 9, No. 5, pp. 1640-1658, 2021. DOI: 10.13189/cea.2021.090533.

(b): Aneke Frank Ikechukwu, Nkwonta Onyeka (2021). Validation of Semi-empirical Models for the Prediction of Swelling Stress for Compacted Unsaturated Expansive Soils. Civil Engineering and Architecture, 9(5), 1640-1658. DOI: 10.13189/cea.2021.090533.

Copyright $(2021$ by authors, all rights reserved. Authors agree that this article remains permanently open access under the terms of the Creative Commons Attribution License 4.0 International License

\begin{abstract}
Unsaturated swelling soil behaviour is governed by the matric suction, thus the predetermination of swelling stress for expansive unsaturated soil requires rigorous procedures. However, some swelling stress equations assume full saturation of the soil, which leads to the over-design of infrastructure. This study focused on the validation of predictive swelling stress models that correlate suction with other soil properties. Three models were developed, and independent data were used for the validation of the developed models. The predicted swelling stress values were compared to the values predicted by the randomly selected predictive models from the literature. Series of initial studies include the determination of basic soil characterization and swelling stress along with soil mineralogical compositions were conducted to determine their geotechnical properties with their corresponding degree of expansiveness. The replicated expansive soils were also studied for suction, using filter paper techniques to obtain the soil's unsaturated parameters. Based on the obtained experimental results, three models were developed using a mathematical software package (NCSS11). Independent data obtained from a group of final year students working on the swelling stress response of expansive unsaturated soils at the geotechnical engineering Laboratory from the University of Johannesburg were used for the validation. The developed models showed good agreement with the independent data, having a coefficient
\end{abstract}

of determination $\left(\mathrm{R}^{2}\right)$ of $0.858,0.931$, and 0.890 for Eq. 4 , 5 , and 6 , respectively. Compared to models selected from literature, which recorded $\mathrm{R}^{2}$ values of 0.796 and 0.636 with an average variance of 0.097 and 0.257 respectively. The correlation variables showed that the degree of expansion represented by swelling stress demonstrated a proportionality with the moisture capacity along the drying and wetting path of the suction curves. Results suggest that the developed models can reasonably predict the swelling stress of compacted expansive soils at high suction values.

Keyword Predictive Models, Swelling Stress, Matric Suction, Unsaturated Soil

\section{Introduction}

Swelling soil is one of the problematic soils that cause damage to various civil engineering structures due to its swelling and shrinking potential upon contact with water. Swelling soils behave differently from other soils due to their tendency to swell and shrink at a very great degree. Because of this swelling and shrinking behavior, expansive soils may cause the following problems in structures or construction projects: Structural damage to lightweight structures such as sidewalks and driveways, 
Lifting of buildings, damage to basements, and building settlement, Cracks in walls and ceilings Damage to pipelines and other public utilities, Lateral movement of foundations and retaining walls due to pressure exerted on vertical walls, Loss of residual shear strength causing instability of slopes, etc. Therefore it is essential to check for the presence of expansive soil and a suitable treatment method should be adopted before commencing any construction projects. In some cases, postconstruction treatment of expansive soil may be required if the situation has not been dealt with before construction. Swelling stress is widely found in semi-arid and arid regions of the world, and South Africa is situated within these areas due to high suction values associated with the soils located within this region [1]. Geotechnical structures such as pavement, foundations, earth dams, and bridges are most vulnerable to volumetric deformation due to swelling activities $[2,3]$. In geotechnical practice, soils are situated in unsaturated conditions, as such structures are located above the groundwater table. Structures constructed on expansive soils are often subjected to large uplift forces caused by swelling, and it induces heaving, cracking, triggering a collapse of foundations and pavements.

Swelling stress is considered imperative for the design and performance analysis of structures. However, oedometer and zero swelling tests are commonly used to evaluate the swelling stress values in engineering practice. Moreover, one of the limitations of the tests includes sample disturbance and time required for full completion of swelling shrinkage cycles. Expansive soils are randomly distributed across the Free State, Northern Cape, KwaZulu-Natal, Mpumalanga, and some parts of the Northwest area of South Africa, with predominant clay minerals known as montmorillonite clay [4]. The swelling potential is influenced by the composition of clay minerals, dry density, void ratio, cementation, and soil macrostructure, though, the most significant factor is clay mineral [5]. Numerous laboratory tests such as free swell, zero swells, loaded swell, restricted swell, constant volume, swell-consolidation, and double oedometer tests, have been proposed in various testing standards to evaluate the swelling stress of compacted soil. Reference [6] determined and compared the swelling characteristics of compacted sand-bentonite and pumice-bentonite mixtures using standard Proctor tests and constant volume swell tests. The results indicated that pumice-bentonite mixtures recorded low dry unit weights, higher optimum moisture contents, and greater swelling potentials than equivalent sand-bentonite mixtures. Reference [7] proposed an empirical equation for swelling pressure using plasticity index, initial water content, and clay content of expansive soils. The proposed equation estimated the swelling pressure with minimum errors within the range of 0.3 to $0.8 \%$. Besides, several empirical relationships have been developed between swelling stress and basic soil index [8-10]. These investigations predicted swell stress value as a function of Atterberg limits, dry density, water content, clay fraction, and cation with a determination coefficient of greater than 0.7. Researchers like (Çimen et al. [11], Vanapalli and $\mathrm{Lu}$ [12], Israr et al. [13]) suggested that swelling stress predictive models could be developed based on investigations performed on a limited number of soils. The challenges of the results are the huge discrepancies between measured and predicted values with $\mathrm{R}^{2}$ of less than 0.6. These models are proclaimed not to be universally valid for all types of expansive soils due to a limited number of samples.

Recent research is geared towards developing empirical methods using the soil-water retention curves (SWRC). The relationship between the volumetric water content and matric suction is used as a tool to predict the swelling stress $[14,15]$. In connection with the studies, expansive unsaturated soils were investigated. The mathematical swelling stress predictive model is developed based on thermodynamic relationships between swelling pressures and suction [16]. According to the results, swelling stress increases with an increase in bentonites quantities, dry density, and total suction. The results are found to be in good concurrence with the experimental data and the data obtained from the literature for the same bentonite. However, several reports in the literature have shown reliable prediction of swelling stress using empirical and semiempirical models for compacted expansive soils [17-19]. In furtherance, some available predictive models are developed for different types of expansive soils, ranging from undisturbed, compacted, and laboratory-built expansive soils. As such, the difference in soil type could significantly influence predictive models. Most times, the percentage of errors between the measured and predicted values varies from $10 \%$ to $67 \%$ for swelling pressure. Despite the existing models, geotechnical engineers still require a deep understanding of the hydromechanical properties of expansive unsaturated soils concerning swelling stress prediction. To extend the hydromechanical response of expansive soils, this study developed three predictive models for three South African expansive soils. The models were developed as a function of gravimetric water content, matric suction, dry unit weight, free swell index, and Atterberg limits. The developed models are suggested to be useful in the prediction of swelling stress for compacted unsaturated expansive soils. Thus, the models are limited as modifications could be required before utilized for another type of soil. Generally, the developed models rationally predicted reliable results for expansive soils when validated with independent data set without going through tedious processes, i.e., the standard oedometer test especially when many tests are required for a particular project. The developed models are also trusted to save high costs accompanied by running oedometer tests and time-consuming. 


\section{Materials and Experimental Programme}

\subsection{Soils}

The soil samples used in this study were collected from 4 different locations across Free State. With different values of plasticity, the soils in this Province are categorized as highly expansive as highlighted in green according to Fig 1. The soil from each site is labelled in alphabetical order as presented in Table 1 .

The collected soil samples classification ranges from $\mathrm{CH}$ to $\mathrm{CL}$, showing predominantly clay with high plasticity according to the unified soil classification system (USCS). Different cores were drilled at each site, and representative soil samples were collected at a depth of $1.2 \mathrm{~m}$, sealed in airtight plastic bags to minimize moisture loss. The soils were batched by blending different particle sizes obtained from dry sieve analysis of each soil. The particle size blending was employed to avoid particle size discrepancies that could affect the test results. The granular and fine batches were thoroughly mixed and air-dried for seven days. Dry sieving was conducted by firstly passing the particles through a $9.5 \mathrm{~mm}$ sieve and subsequently sieved using $4.75 \mathrm{~mm}$ and $75 \mu \mathrm{m}$ sieves to separate fines, sand, and gravel. The soils that passed through a $75 \mu \mathrm{m}$ sieve were further subject to a hydrometer test to differentiate percentages of silt and clay for the representative soils following ASTM D1140 [20]. The cumulative percentages of the soils passing through the American Society for Testing and Materials (ASTM) sieve size of \#200 vary between $75 \%$ and $100 \%$, as presented in Table 1.

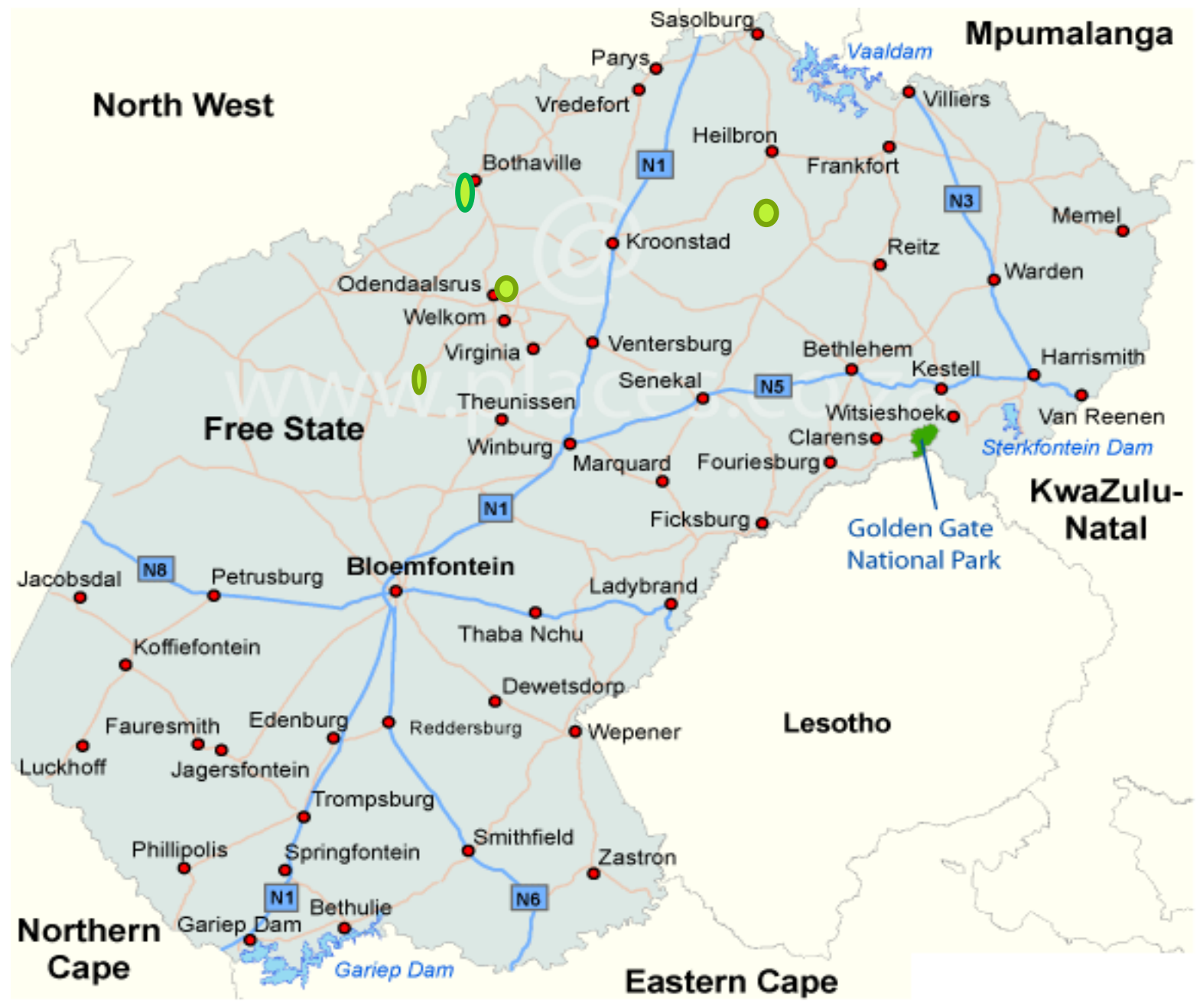

Figure 1. The visited sites are highlighted with green colour. 
Table 1. Summary of soil properties used in the study.

\begin{tabular}{|c|c|c|c|c|c|c|c|c|c|}
\hline \multicolumn{2}{|c|}{ Designation } & \multirow[t]{2}{*}{ LL (\%) } & \multirow[t]{2}{*}{$\mathrm{I}_{\mathrm{P}}(\%)$} & \multirow[t]{2}{*}{$\mathrm{L}_{\mathrm{S}}(\%)$} & \multicolumn{2}{|c|}{ Fines $(\%)$} & \multirow[t]{2}{*}{ Gravel (\%) } & \multirow[t]{2}{*}{$\mathrm{G}_{\mathrm{s}}$} & \multirow[t]{2}{*}{ USCS } \\
\hline Sites & Soils & & & & Silt & Sand & & & \\
\hline \multirow[t]{3}{*}{ BLM 1} & Soil A & 69.11 & 43.93 & 18.9 & 71.38 & 18.32 & 10.30 & 2.75 & $\mathrm{CH}$ \\
\hline & Soil B & 65.23 & 38.11 & 22.13 & 62.45 & 21.24 & 16.31 & 2.78 & $\mathrm{CH}$ \\
\hline & Soil C & 64.18 & 35.71 & 16.42 & 59.20 & 27.19 & 13.61 & 2.74 & $\mathrm{CH}$ \\
\hline \multirow[t]{3}{*}{ WLK 2} & Soil A & 61.30 & 38.25 & 13.68 & 55.25 & 28.83 & 15.92 & 2.77 & $\mathrm{CH}$ \\
\hline & Soil B & 74.32 & 50.11 & 15.48 & 68.11 & 18.18 & 13.71 & 2.73 & $\mathrm{CH}$ \\
\hline & Soil C & 45.20 & 22.10 & 11.24 & 39.27 & 40.24 & 20.49 & 2.75 & $\mathrm{CL}$ \\
\hline \multirow[t]{3}{*}{ BHM 3} & Soil A & 75.41 & 35.47 & 13.83 & 67.98 & 20.92 & 11.10 & 2.71 & $\mathrm{CH}$ \\
\hline & Soil B & 71.25 & 29.54 & 12.93 & 64.78 & 21.98 & 13.24 & 2.76 & $\mathrm{CH}$ \\
\hline & Soil C & 66.24 & 24.13 & 15.24 & 58.23 & 28.66 & 13.11 & 2.74 & $\mathrm{CH}$ \\
\hline \multirow[t]{3}{*}{ WBG 4} & Soil A & 71.54 & 48.21 & 16.71 & 62.52 & 20.82 & 16.66 & 2.73 & $\mathrm{CH}$ \\
\hline & Soil B & 42.61 & 19.32 & 8.11 & 35.21 & 42.15 & 22.64 & 2.69 & CL \\
\hline & Soil C & 45.28 & 21.31 & 9.28 & 38.54 & 40.21 & 21.25 & 2.68 & CL \\
\hline
\end{tabular}

${ }^{*} \mathrm{G}_{\mathrm{s}}=$ specific gravity **USCS: universal soil classification system*

Table 2. Soil mineralogical compositions (X-ray diffraction result)

\begin{tabular}{|c|c|c|c|c|c|c|c|}
\hline Sites & Soils & Smectite & Silica & K-feldspar & Plagioclase & Illite & Calcite \\
\hline BLM 1 & Soil A & 71.74 & 13.41 & 9.91 & 1.85 & 1.89 & 1.22 \\
\hline & Soil B & 67.05 & 19.98 & 10.66 & 2.31 & $<<$ & $<<$ \\
\hline & Soil C & 71.74 & 13.40 & 9.91 & 1.85 & 1.89 & 1.22 \\
\hline WLK 2 & Soil A & 61.30 & 13.25 & 6.95 & 5.15 & 8.13 & 5.22 \\
\hline & Soil B & 70.18 & 11.12 & 5.14 & 4.11 & 2.31 & 3.14 \\
\hline & Soil C & 34.26 & 30.75 & 20.32 & 7.04 & 2.11 & 5.52 \\
\hline BHM 3 & Soil A & 64.23 & 14.36 & 8.93 & 5.98 & 4.58 & 2.10 \\
\hline & Soil B & 67.47 & 15.54 & 8.49 & 4.15 & 3.21 & 1.14 \\
\hline & Soil C & 65.50 & 10.45 & 7.03 & 6.37 & 6.14 & 4.51 \\
\hline WBG 4 & Soil A & 63.37 & 20.34 & 10.71 & 1.80 & 2.43 & 1.35 \\
\hline & Soil B & 61.14 & 11.93 & 19.01 & 2.63 & 3.31 & 1.98 \\
\hline & Soil C & 59.53 & 27.47 & 9.19 & 3.81 & $<<$ & $<<$ \\
\hline
\end{tabular}

*BLM: Bloemfontein, *WLK: Welkom *BHM: Bethlehem* WBG: Winburg

The geotechnical index properties of the investigated soils as presented in Table 1 show that the liquid limit and shrinkage results confirm that soils are of a high degree of expansiveness. The plasticity values of the soils are within the range of 35 to $50 \%$, whereas the obtained linear shrinkage is within the values range of $15 \%$ to $23 \%$. In the winter season, when the samples were sampled, the soil generally experiences a net water deficit given the semi-arid climate prevalent in the province. The degree of saturation ranges from 82 to 92 and the value reflects the unsaturated state of the samples in the field, as the high liquid limit and plastic limit indicate the high-water adsorption capability of the soils. Thus, it could be attributed to the presence of expansive clay minerals such as smectite, montmorillonite, Kaolinite-and vermiculite. The percent of the fine-grained and clay minerals of the soils suggests that the soils have a high-water retention capacity. Overall, the soil was classified as $\mathrm{CH}$ (clay with high plasticity) with few classified as CL (clay with low plasticity) according to the Unified Soil Classification System (USCS).

The index properties of clayey material depend on the type and content of clay minerals, which considerably influence the swelling stress of expansive soils [21]. Therefore, to evaluate the mineralogical compositions responsible for swelling activities, the investigated soils were subject to X-Ray Diffraction (XRD) testing using the Rigaku TTRA III diffractometer, and tests were performed at $\mathrm{Cu} \mathrm{K \alpha}$ radiation $(1.5418 \AA)$ level as presented in Table 2 . The presented XRD results analysis also confirms that the investigated soils are expansive consisting of dominant phases of, smectite, illite, silica, calcite, and other clay minerals evaluated at trace level. 


\subsection{Sample Preparations}

Prior to sample preparation, a Proctor compaction test was carried out on the soils following ASTM D-698, [22]. Specifically, this test is designed to determine the optimum moisture content (OMC) of soil with its corresponding maximum dry density (MDD). Generally, the investigated soils respond in a similar trend as the optimum moisture content ranges between $18.24 \%$, to $33.31 \%$, whereas the dry densities at the optimum moisture content range from $17.74 \mathrm{kN} / \mathrm{m}^{3}$ to $21.85 \mathrm{kN} / \mathrm{m}^{3}$ for the investigated soils. This implies that the soils are composed of high plasticity with significant swelling potentials. The soil samples were prepared at various MDDs with their corresponding moisture content, as initially obtained from the compaction test. Given quantities of soils were weighted and thoroughly mixed after representative amounts of water were added. The mixing continued until homogeneous soil mixtures were obtained. The soil mixtures were covered in airtight plastic bags for $8 \mathrm{~h}$ before specimen fabrication to ensure uniform distribution of moisture. The specimens were deemed suitable for testing when the density after preparation was at least $97 \%$ of the targeted MDD obtained from the preliminary compaction test for each soil.

\section{Experimental Testing Procedures}

Series of laboratory Civil Engineering testing programs routinely used to measure Geotechnical properties were conducted on the soil materials. The free swell index was conducted on the studied soils according to the Indian standard Is- 2720; (Part 40) [23] test method to evaluate the swelling potential of the soils. The soils were passed through $425 \mu \mathrm{m}$ sieve size (\#40) and the soils were oven-dried at a temperature of $115^{\circ} \mathrm{C}$. The expression in Equation 1 is used to evaluate the FSI values.

$$
\mathrm{FSI}=\left[\left(\mathrm{V}_{\mathrm{s}}-\mathrm{V}_{\mathrm{k}}\right) / \mathrm{V}_{\mathrm{k}}\right] \times 100 \%
$$

Where FSI is the free Swell Index, $V_{k}$ is the volume of soil in kerosene and $V_{S}$ is the volume of soil in water. The samples contained in the kerosene jar are used as the control, due to the non-expansiveness of the soils in kerosene.

In this study, matric suction was determined by the filter paper method in conformance with ASTM 5298 [24]. After 14 days, the contact and no-contact filter papers were retrieved, weighed and their water contents were determined following the procedures suggested by [25]. The filter paper moisture contents were converted to matric suction using Eq 2.

$$
\log (\mathrm{kPa})=-0.0688 \omega+5.056
$$

where $\omega$ is filter paper water content.

\subsection{Zero Swelling Test}

The ZST was carried out following IS 2720 (Part 41) [26]. The soil samples passing through ASTM sieve size of $4.75 \mathrm{~mm}$ (\#4) were used. The specimens were prepared according to the initial compaction test, at various moisture contents and corresponding dry unit weights. The specimens were demolding and cut into slices of $25-\mathrm{mm}$ height and $75 \mathrm{~mm}$ in diameter bearing the shape of a consolidation ring, and the oedometer ring was fitted into the sliced specimens. It was then wetted on a high-pressure oedometer frame under vertical stress of 0.1 MPa using distilled water as the specimens are loaded. Once the swelling starts, the vertical load was increased to prevent any vertical swelling. During this process, maximum swell and the vertical strain was allowed. When the swelling was complete, the total applied load was recorded. This is defined as swelling stress and this method has been widely employed internationally in determining the soil swelling stress [27]. The zero swelling experimental setups are shown in Fig 2.

The same procedure continued until no additional swelling was recorded on the dial gauge. The swelling stress of the specimens was computed according to Equation 3.

$$
\mathrm{P}_{\mathrm{S}}(\mathrm{kPa})=\left(\sum_{\mathrm{i}}^{\mathrm{n}}=1 \mathrm{M}_{\mathrm{i}} \times \mathrm{g} \times \mathrm{b}_{\mathrm{r}} / \pi\left(\varnothing^{2}\right) / 4\right) / 100
$$

where $\mathrm{P}_{\mathrm{s}}$ is the swelling stress in $\mathrm{kPa}, \sum_{i}^{n}=1 M_{i}$ is the total sum of surcharge, $\mathrm{g}$ is the acceleration due to gravity $9.81 \mathrm{~m} / \mathrm{s}^{2}, b_{r}$ is the beam ratio of the oedometer arm, $\pi\left(\varnothing^{2}\right) / 4$ is the internal area of the ring.
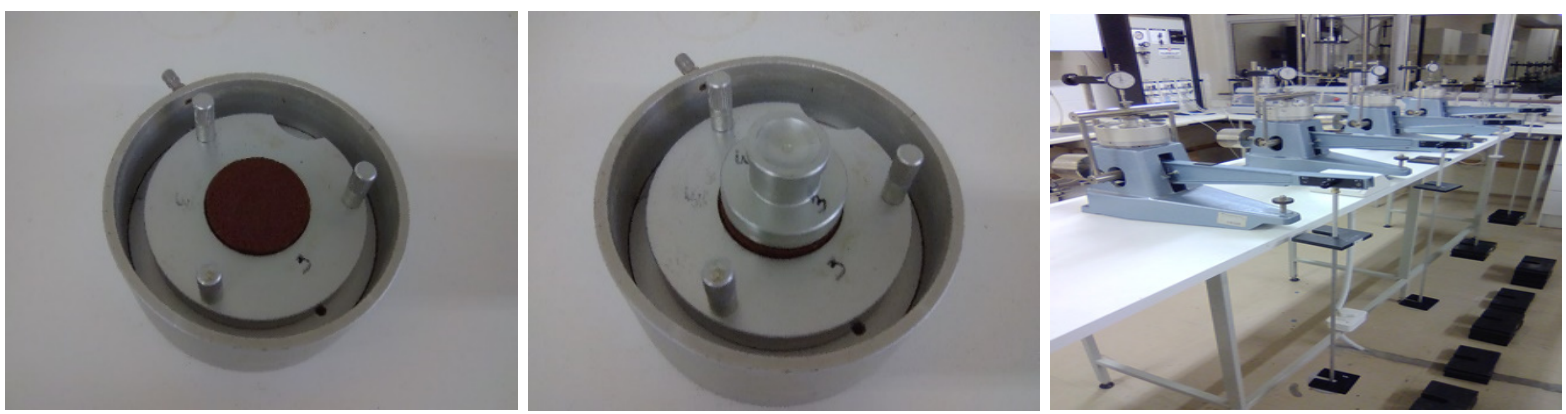

Figure 2. Zero swelling test setup 


\section{Results and Discussions}

The experimental test results covered the following test results: Atterberg limit, free swell index, swelling stress, and filter paper test. The laboratory results illustrate the geotechnical properties, and the results were carefully interpreted using an average of three specimens of each tested soil to eliminate discrepancies that might affect the test results. The study first evaluates the relationship between swelling stress and plasticity index. Subsequently, the correlations were used to develop predictive mathematical models for swelling stress.

\subsection{Swelling Stress - PI Correlation}

The interaction between swelling stress and the plasticity index of compacted expansive soil is illustrated in Fig 3. The soils demonstrate that swelling stress increases as the plasticity index increased. This increase was within the range of $35.71 \%$ to $43.93 \%$ with the corresponding swelling stress of $210 \mathrm{kPa}$ to $880 \mathrm{kPa}$, respectively. There is a great proportionality between the swelling stress and soil plasticity as the correlation for coefficients of determination are in the range of $\mathrm{R}^{2}=0.982$ to 0.960 . The test results could be associated with the fact that expansive soil undergone hydromechanics transformation from liquid limit to plastic limit and finally to plasticity. At these transformational phases, the soil swelling potential increases. The result agrees with the study published elsewhere by $[28,29]$.

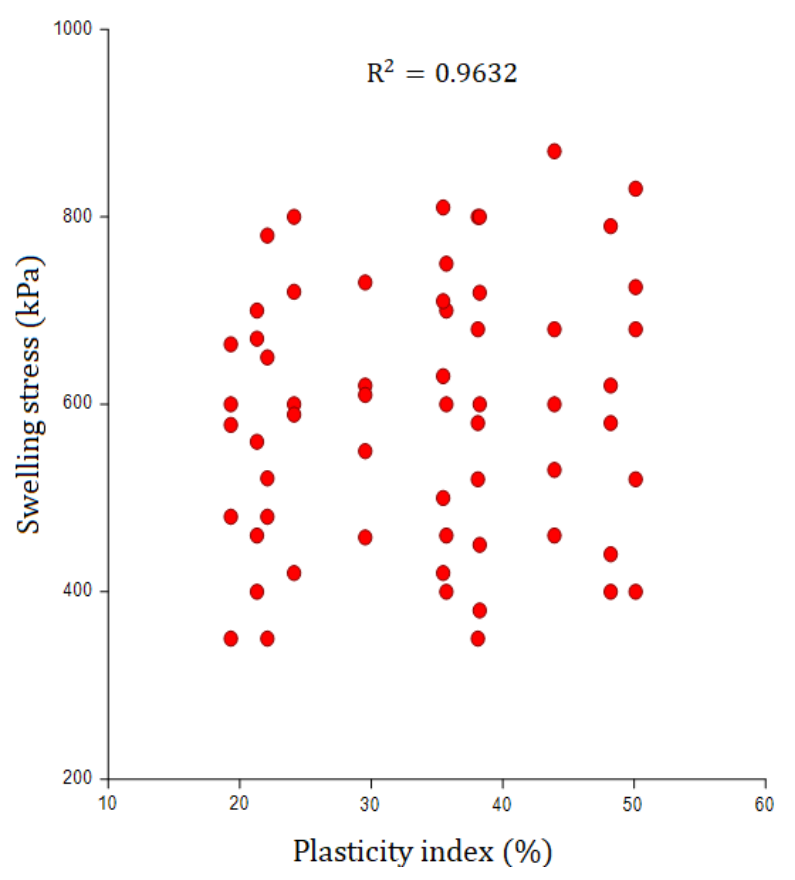

Figure 3. Swelling stress and plasticity index relationship

\subsection{Swelling Stress - FSI Relationship}

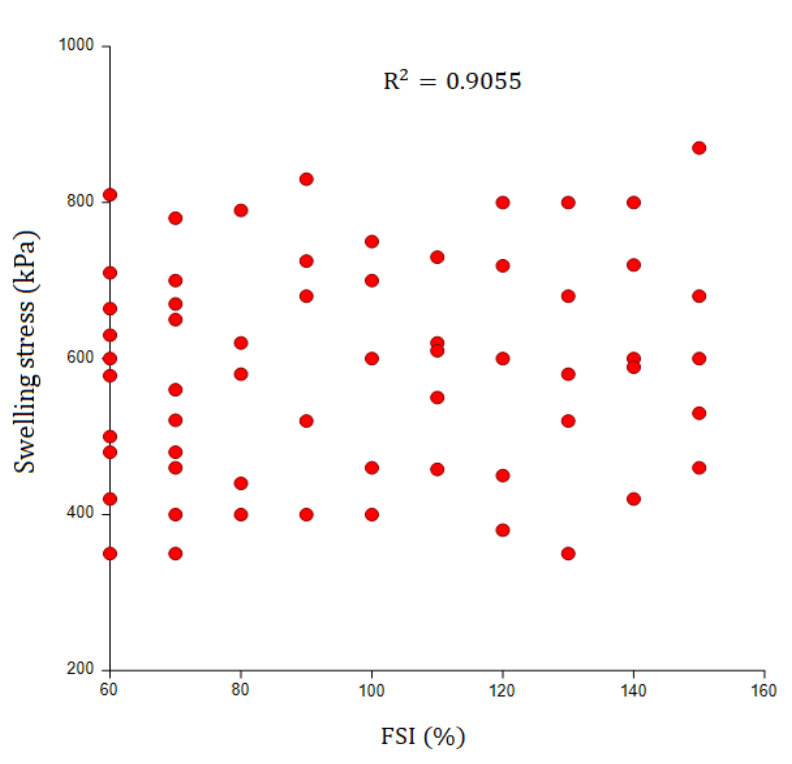

Figure 4. Swelling stress and FSI correlation

The swelling stress and free swell index values obtained at the dry side of moisture content were plotted as shown in Fig 4. It is observed that there is a great proportionality of the linear relationship between swelling stress and FSI with coefficient variability $\mathrm{R}^{2}=0.9055$. Generally, it is noted that all the tested soils indicate a band of scattered points that rendered increasing trends of swelling stress with an increase in the free swell index. This implies that the soils are of high plasticity and could be attributed to their mineralogical composition. The tremendous amount of pressure exerted by expansive soil with high plasticity during swelling is a source of damages to lightweight structures such as shallow foundations and pavements. Thus, the relationship between the swelling stress and FSI is dominated by a combination of factors including the water content and percentage of available clay minerals. Several studies have been done on correlated clay content to swelling potentials. The soil with a higher percentage of smectite clay minerals renders higher swelling stress values and absorbed the highest amount of water during FSI testing. The FSI of the investigated soils ranges from $80 \%$ to $150 \%$ swelling of the measured initial percentage volumes due to sufficient specific surface with intermolecular forces of attractions. Based on the test results the mechanism of swelling for the expansive soil can be explained as follows. During the process of saturation water, the divalent cations $\left(\mathrm{Ca}^{2+}, \mathrm{Mg}^{2+}\right)$ in the surface soil layer migrate downward along with water molecules and aggregate around clay particles, eventually form the electrical environment. In this process, the cation exchange with expansive soil occurs where the bivalent cations $\left(\mathrm{Ca}^{2+}, \mathrm{Mg}^{2+}\right)$ enter into the diffuse double-layer (DDL) of clay particles and interlayer of montmorillonite crystals, resulting in the modification effect to restrain the swelling potential of the lower expansive soil layer. On the other hand, the hydrated exchangeable cations adhere 
to the soil particles and formed the adsorbed water film surrounding the aggregates, which produces crystalline swelling and diffuse double-layer swelling. Therefore, the FSI has a significant impact on swelling stress values. Reference [30, 31] pointed out that the behaviour of the expansive soils depends on the fraction of macropores among soil particles, which is likely to account for an increase in swelling stress under moisture conditions.

\subsection{Swelling Stress - Gravimetric Moisture Content Relationship}

The swelling stress is classified in terms of its threat to structures, swelling stress values that are less than $<150$ $\mathrm{kPa}$ is classified as non-critical. Whereas the swelling stress values within the ranges of $150-170 \mathrm{kPa}$ and 180 $250 \mathrm{kPa}$ are considered marginal and critical, respectively. Furthermore, swelling stress values greater than $250 \mathrm{kPa}$ are classified as very critical according to [26]. The obtained swelling stress values of the investigated soils range from $250 \mathrm{kPa}$ to $1000 \mathrm{kPa}$. This implies that the investigated soils are classified as critical to very critical classification. These values can generate problems and trigger serious consequences for existing structures. The scattered plot in Fig. 5 illustrates the correlation between swelling stress and moisture content of the investigated soils. It is noted that water content increases with a decrease in swelling stress. This implies that the soils recorded higher swelling stress values at low densities. The lower swelling stress values were noted at the wet side of the optimum as the dry density increases. The results concord with the outcome of the investigation conducted by [32] on the swelling pressure and meso-mechanism of Gaussian distribution under constant volume conditions, which revealed that the relation of expansive stress and initial moisture content depends on the change in the microstructure with diverse moisture contents. In addition, dry density and vertical stress influence expansive properties were also correlated with swelling stress.

The received correlation between water content and swelling stress is best reflected by a linear function and the regression coefficient $\mathrm{R}^{2}$ of $>0.911$. However, the relation between expansive stress and moisture content in this study is in line with a report published by Çimen et al. [33] which demonstrated that expansive stress decreased while moisture content was increased. This difference could be associated with samples prepared at the dry side of the optimum which rendered smaller initial water content with more macropores. Therefore, the internal space was enough to allow for higher swelling stress. With an increase in the initial water content, the proportion of macropores decreased, causing the swelling stress to become large due to the restricted space to swell during the wetting process. A drop in swelling stress was observed as the initial moisture content shifted from the dry to wet side of the optimum.

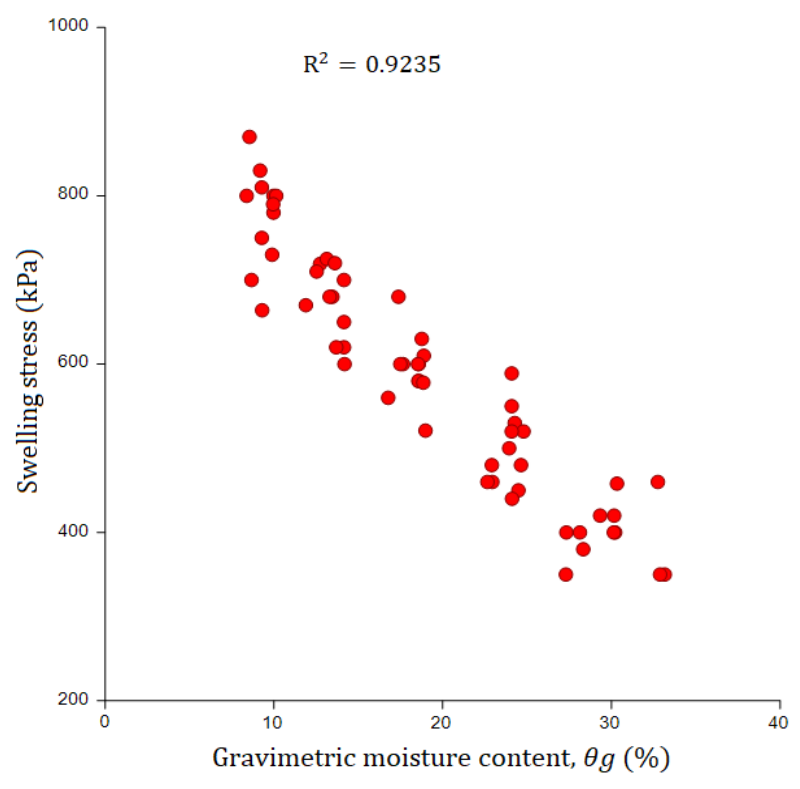

Figure 5. Swelling stress and gravimetric moisture content correlation

\subsection{Swelling Stress - Matric Suction Relationship}

The suction and swelling stress relationships are presented in Fig 6. It is noted that swelling stress increases with increasing soil matric suction. The swelling stress and suction correlation are bi-linear and are typically described with linear curve fitting. Thus, the relationship portrayed an increase in swelling stress at a rapid rate with soil suction $[34,35]$. Moreover, at the initial water content blow the plasticity index, the swelling stress and matric suction recorded the highest values, respectively. At a phase beyond the plasticity index and optimum moisture content both swelling stress and matric suction, continue to increase. This implies that water content filled up the voids within the soil pores, therefore allowing no space for expansion. However, the type of clay minerals could also impact the response of the investigated soils. The obtained result agrees with the study initially published by [36], which states that the high content of smectite clay minerals influences the suction and swelling stress value of expansive soil up to $68 \%$. The soil with low content of smectite clay minerals records low swelling stress and suction values. Thus, matric suction correlation with swelling stress is stress state variables of unsaturated soils that account for volume changes.

Based on the extrapolation of gravimetric moisture content versus, and dry densities used in this study with the corresponding matric suction values, $(\psi)$, all test data points were interpolated using model 4 , and the suction matric curve against swelling stress was obtained as shown in Fig 6.

$$
P_{s}=\chi+0.0585 \psi, R^{2}=0.9043 \text { (Authors) }
$$

where $P_{S}$ is the swelling stress, 0.0585 is the fitting 
parameter and 0.9043 is the coefficient of determination calculated from the slope of swelling stress against matric suction curve, which is relatively influenced by dry unit weight and moisture content of the soils as prescribed on the curve.

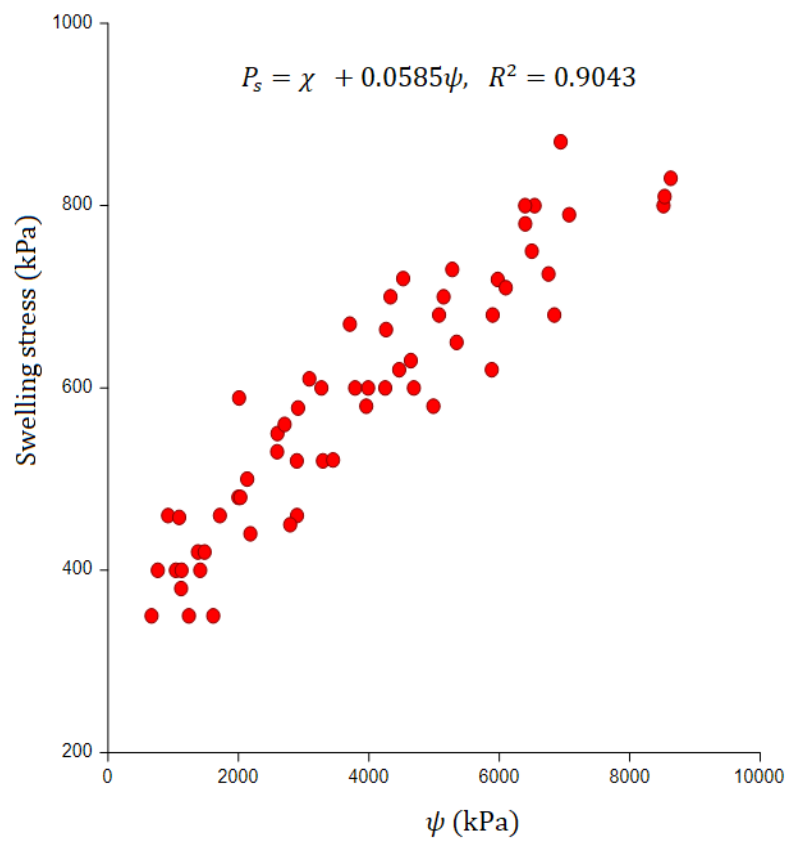

Figure 6. Swelling stress and suction correlation

Generally, the correlation between the swelling stress, plasticity index, FSI, GMC, dry density and matric suctions has been evaluated. A great proportionality between the swelling stress and matric suction rendered a variability coefficient of $\mathrm{R}^{2}=0.9043$. However, this bi-linear relationship is influenced by soil mineralogy. Therefore, the investigated unsaturated expansive soil collected across Bloemfontein could trigger significant upward swelling stress beyond $250 \mathrm{kPa}$. Beyond this value, swelling stress is considered critical for lightweight structures. The presence of clay minerals responsible for swelling activities recorded a considerable influence on the swelling stress of the investigated soils.

Suction demonstrates the water retention capacity of the expansive soil, which is the driving force of water flow in unsaturated soil. Table 3 presents the variation of the matric suction with gravimetric moisture content. It is noted that the total and matric suction curves for the investigated soils response with gravimetric moisture content in a similar trend. Therefore, the gravimetric moisture content and matric suction values are summarized in Table 3. At the dry side of the optimum, the values of matric suction were high within a greater moisture range. A change in total suction is fundamentally equivalent to a variation in matric suction. Thus, soils with a high content of smectite clay minerals recorded the highest suction value because of their high potentials to retain water. The results demonstrate that matric suction dominated $85 \%$ of the total suction component as reported by Leong et. al, [37], which could be attributed to the soil's capillarity, pore size distribution, and hydromechanical interactions which are highly dependent on the soil mineralogy.

Table 3. Summary of soil properties used in the study

\begin{tabular}{|c|c|c|c|c|c|c|c|c|c|c|}
\hline \multicolumn{2}{|c|}{ Soil designation } & $\begin{array}{c}\text { GMC } \\
(\%)\end{array}$ & $\mathbf{I}_{\mathrm{P}}(\mathbf{\%})$ & $\begin{array}{c}\gamma_{\mathbf{d}} \\
\mathbf{k N} / \mathbf{m}^{3} \\
\end{array}$ & $\begin{array}{l}\text { FSI } \\
(\%)\end{array}$ & $\begin{array}{c}\Psi_{\mathrm{m}} \\
(\mathrm{kPa})\end{array}$ & $\mathrm{S} / \mathbf{1 0 0}$ & $\begin{array}{c}\mathbf{P}_{\text {sm }} \\
(\mathrm{kPa})\end{array}$ & Classification & USCS \\
\hline \multirow[t]{12}{*}{ BLM 1} & Soil A & & & & & & & & & \\
\hline & & 8.55 & 43.93 & 12.45 & 150 & 6941 & 0.85 & 870 & \multirow{5}{*}{ Very high } & $\mathrm{CH}$ \\
\hline & & 13.46 & 43.93 & 16.63 & 150 & 5076 & 0.85 & 680 & & \\
\hline & & 17.65 & 43.93 & 17.32 & 150 & 3789 & 0.85 & 600 & & \\
\hline & & 24.27 & 43.93 & 15.90 & 150 & 2593 & 0.85 & 530 & & \\
\hline & & 32.75 & 43.93 & 12.88 & 150 & 921 & 0.85 & 460 & & \\
\hline & Soil B & & & & & & & & & \\
\hline & & 9.97 & 38.11 & 12.47 & 130 & 8517 & 0.94 & 800 & \multirow{5}{*}{ High } & $\mathrm{CH}$ \\
\hline & & 13.30 & 38.11 & 15.62 & 130 & 6843 & 0.94 & 680 & & \\
\hline & & 18.58 & 38.11 & 16.93 & 130 & 4989 & 0.94 & 580 & & \\
\hline & & 24.79 & 38.11 & 14.15 & 130 & 3295 & 0.94 & 520 & & \\
\hline & & 33.16 & 38.11 & 12.12 & 130 & 1613 & 0.94 & 350 & & \\
\hline
\end{tabular}


1648 Validation of Semi-empirical Models for the Prediction of Swelling Stress for Compacted Unsaturated Expansive Soils

Table 3 Continued

\begin{tabular}{|c|c|c|c|c|c|c|c|c|c|c|}
\hline & Soil C & & & & & & & & & \\
\hline & & 9.28 & 35.71 & 11.45 & 100 & 6498 & 0.85 & 750 & \multirow{5}{*}{ High } & $\mathrm{CH}$ \\
\hline & & 14.15 & 35.71 & 17.61 & 100 & 5145 & 0.85 & 700 & & \\
\hline & & 18.58 & 35.71 & 16.59 & 100 & 4250 & 0.85 & 600 & & \\
\hline & & 22.94 & 35.71 & 16.93 & 100 & 2898 & 0.85 & 460 & & \\
\hline & & 27.33 & 35.71 & 13.47 & 100 & 1040 & 0.85 & 400 & & \\
\hline WLK 2 & Soil A & & & & & & & & & \\
\hline & & 8.38 & 38.25 & 16.07 & 120 & 6541 & 0.92 & 830 & \multirow{5}{*}{ High } & $\mathrm{CH}$ \\
\hline & & 12.73 & 38.25 & 18.92 & 120 & 5976 & 0.92 & 725 & & \\
\hline & & 17.49 & 38.25 & 19.35 & 120 & 4689 & 0.92 & 680 & & \\
\hline & & 24.49 & 38.25 & 17.52 & 120 & 2793 & 0.92 & 520 & & \\
\hline & & 28.33 & 38.25 & 16.18 & 120 & 1121 & 0.92 & 400 & & \\
\hline & Soil B & & & & & & & & & \\
\hline & & 9.18 & 50.11 & 15.45 & 90 & 8628 & 0.97 & 780 & \multirow{5}{*}{ High } & $\mathrm{CH}$ \\
\hline & & 13.13 & 50.11 & 17.52 & 90 & 6754 & 0.97 & 650 & & \\
\hline & & 17.38 & 50.11 & 18.52 & 90 & 5898 & 0.97 & 521 & & \\
\hline & & 24.09 & 50.11 & 18.89 & 90 & 2895 & 0.97 & 480 & & \\
\hline & & 30.22 & 50.11 & 15.58 & 90 & 1413 & 0.97 & 350 & & \\
\hline & Soil C & & & & & & & & & \\
\hline & & 9.97 & 22.10 & 14.17 & 70 & 6398 & 0.83 & 810 & \multirow{5}{*}{ Moderate } & CL \\
\hline & & 14.15 & 22.10 & 15.86 & 70 & 5345 & 0.83 & 710 & & \\
\hline & & 18.98 & 22.10 & 16.83 & 70 & 3450 & 0.83 & 630 & & \\
\hline & & 24.64 & 22.10 & 15.95 & 70 & 1998 & 0.83 & 500 & & \\
\hline & & 32.88 & 22.10 & 13.02 & 70 & 1240 & 0.83 & 420 & & \\
\hline \multirow[t]{12}{*}{ BHM 3} & Soil A & & & & & & & & & \\
\hline & & 9.28 & 35.47 & 16.47 & 60 & 8534 & 0.95 & 730 & \multirow{5}{*}{ High } & $\mathrm{CH}$ \\
\hline & & 12.53 & 35.47 & 19.46 & 60 & 6098 & 0.95 & 620 & & \\
\hline & & 18.76 & 35.47 & 21.83 & 60 & 4643 & 0.95 & 610 & & \\
\hline & & 23.94 & 35.47 & 20.07 & 60 & 2134 & 0.95 & 550 & & \\
\hline & & 29.33 & 35.47 & 16.16 & 60 & 1378 & 0.95 & 458 & & \\
\hline & Soil B & & & & & & & & & \\
\hline & & 9.89 & 29.54 & 15.45 & 110 & 5278 & 0.97 & 790 & \multirow{5}{*}{ Very high } & $\mathrm{CH}$ \\
\hline & & 14.15 & 29.54 & 19.23 & 110 & 4465 & 0.97 & 620 & & \\
\hline & & 18.88 & 29.54 & 20.89 & 110 & 3087 & 0.97 & 580 & & \\
\hline & & 24.09 & 29.54 & 18.96 & 110 & 2598 & 0.97 & 440 & & \\
\hline & & 30.33 & 29.54 & 15.96 & 110 & 1091 & 0.97 & 400 & & \\
\hline
\end{tabular}


Table 3 Continued

\begin{tabular}{|c|c|c|c|c|c|c|c|c|c|c|}
\hline & Soil C & & & & & & & & & \\
\hline & & 10.13 & 24.13 & 18.13 & 140 & 6395 & 0.95 & 664 & \multirow{5}{*}{ Very high } & $\mathrm{CH}$ \\
\hline & & 13.61 & 24.13 & 21.63 & 140 & 4525 & 0.95 & 600 & & \\
\hline & & 18.54 & 24.13 & 22.84 & 140 & 3272 & 0.95 & 578 & & \\
\hline & & 24.09 & 24.13 & 21.71 & 140 & 2010 & 0.95 & 480 & & \\
\hline & & 30.16 & 24.13 & 18.83 & 140 & 1481 & 0.95 & 350 & & \\
\hline \multirow[t]{18}{*}{ WBG 4} & Soil A & & & & & & & & & \\
\hline & & 9.95 & 48.21 & 16.45 & 80 & 7071 & 0.92 & 700 & \multirow{5}{*}{ High } & $\mathrm{CH}$ \\
\hline & & 13.69 & 48.21 & 18.83 & 80 & 5884 & 0.92 & 670 & & \\
\hline & & 18.56 & 48.21 & 20.59 & 80 & 3959 & 0.92 & 560 & & \\
\hline & & 24.11 & 48.21 & 17.96 & 80 & 2183 & 0.92 & 480 & & \\
\hline & & 30.14 & 48.21 & 15.96 & 80 & 1128 & 0.92 & 430 & & \\
\hline & Soil B & & & & & & & & & \\
\hline & & 9.30 & 19.32 & 17.67 & 60 & 4263 & 0.82 & 870 & \multirow{5}{*}{ Moderate } & $\mathrm{CL}$ \\
\hline & & 14.18 & 19.32 & 19.96 & 60 & 3989 & 0.82 & 680 & & \\
\hline & & 18.85 & 19.32 & 22.43 & 60 & 2914 & 0.82 & 600 & & \\
\hline & & 22.91 & 19.32 & 20.97 & 60 & 2029 & 0.82 & 530 & & \\
\hline & & 27.30 & 19.32 & 19.76 & 60 & 667 & 0.82 & 460 & & \\
\hline & Soil C & & & & & & & & & \\
\hline & & 8.67 & 21.31 & 19.73 & 70 & 4331 & 0.85 & 800 & \multirow{5}{*}{ Moderate } & $\mathrm{CL}$ \\
\hline & & 11.89 & 21.31 & 21.13 & 70 & 3708 & 0.85 & 680 & & \\
\hline & & 16.77 & 21.31 & 22.64 & 70 & 2707 & 0.85 & 580 & & \\
\hline & & 22.65 & 21.31 & 22.41 & 70 & 1715 & 0.85 & 520 & & \\
\hline & & 28.13 & 21.31 & 21.23 & 70 & 763 & 0.85 & 350 & & \\
\hline
\end{tabular}

\section{Development of Multi-regression Predictive Models for Swelling Stress}

The variables presented in Table 3 are utilized as correlation matrices to perform multi-regression analysis using the NCSS11 program. The developed model in this investigation is based on the plasticity index, FSI, gravimetric moisture contents, and matric suction of highly expansive soils across Bloemfontein. These properties were selected due to their high coefficient of determination $\left(\mathrm{R}^{2}\right)$ values as presented earlier in this study. The soil properties are designated as independent variables, whereas swelling stress is set as a dependent variable. it was considered desirable to perform multilinear regression analysis based on each of the measured soil properties to predict the dependent variable and validate models with an independent dataset. Regression analysis is applied to assess the relationship between soil properties and swelling stress particularly for expansive soils [38, 39]. The experimental data in Table 3 were used to develop the models, due to the influence of FSI, GMC, P.I., and matric suction on swelling stress.

The correlation matrix related to model 5 and 6 are presented in Table 4, as two constitutive models were developed to predict the swelling stress of compacted unsaturated expansive soils: Model 5 is built up with the following independent variables: plasticity index (P.I.), dry unit weight $\left(\gamma_{d}\right)$, free swell index (FSI), and matric suction $\left(\psi_{\mathrm{m}}\right)$ with coefficients of correlation presented as: $\lambda_{1} \lambda_{2}, \lambda_{3}, \lambda_{4}$, and the intercept $\lambda_{0}$.

$$
\left.\lambda_{0}-\lambda_{1} \text { (P.I. }\right)+\lambda_{2}\left(\gamma_{\mathrm{d}}\right)+\lambda_{3}(\mathrm{FSI})+\lambda_{4}\left(\psi_{\mathrm{m}}\right)[\text { Authors }]
$$

Model 6 is developed with the following independent variables: dry unit weight $\left(\gamma_{\mathrm{d}}\right)$, free swell index (FSI), and matric suction $\left(\psi_{\mathrm{m}}\right)$ with coefficients of correlation been summarized as: $\xi_{1}, \xi_{2}, \xi_{3}$ and the intercept $\xi_{0}$.

$$
\mathrm{P}_{\mathrm{S}}=\xi_{0}+\xi_{1}\left(\gamma_{\mathrm{d}}\right)+\xi_{2}(\mathrm{FSI})+\xi_{3}\left(\psi_{\mathrm{m}}\right)[\text { Authors }]
$$


Table 4. Parameters symbols and their corresponding values

\begin{tabular}{|c|c|c|c|}
\hline Denotations & Meaning & Values & $\mathrm{R}^{2}$ \\
\hline \multicolumn{4}{|c|}{ Model $5=\boldsymbol{P}_{s}=\left\{\boldsymbol{P I}, \gamma_{d}, \boldsymbol{F S I}, \boldsymbol{\Psi}_{\mathrm{m}}\right\}$} \\
\hline$\lambda_{0}$ & Intercept & 256.40 & - \\
\hline$-\lambda_{1}$ & Coff. for Plasticity index & 1.87 & - \\
\hline P.I. & Plasticity index & - & 0.6523 \\
\hline$\lambda_{2}$ & Coff. for dry unit weight & 5.470 & - \\
\hline$\gamma_{\mathrm{d}}$ & dry unit weight & - & 0.7564 \\
\hline$\lambda_{3}$ & Coff. for FSI & 0.546 & - \\
\hline FSI & Free swell index & - & 0.7555 \\
\hline$\lambda_{4}$ & Coff. for $\psi_{\mathrm{m}}$ & 0.063 & - \\
\hline$\Psi_{\mathrm{m}}$ & Matric suction & & 0.9715 \\
\hline \multicolumn{4}{|c|}{ Model $6=\boldsymbol{P}_{\boldsymbol{s}}=\left\{\boldsymbol{\gamma}_{\boldsymbol{d}}, \boldsymbol{F S I}, \boldsymbol{\Psi}_{\mathrm{m}}\right\}$} \\
\hline$\xi_{0}$ & Intercept & 178.75 & - \\
\hline$\xi_{1}$ & Coff. for dry unit weight & 7.35 & - \\
\hline$\gamma_{\mathrm{d}}$ & dry unit weight & - & 0.4228 \\
\hline$\xi_{2}$ & Coff. for FSI & 0.423 & - \\
\hline FSI & Free swell index & - & 0.7618 \\
\hline$\xi_{3}$ & Coff. for $\psi_{\mathrm{m}}$ & 0.061 & - \\
\hline$\Psi_{\mathrm{m}}$ & Matric suction & - & 0.9568 \\
\hline \multicolumn{4}{|c|}{ Multi-Regression report } \\
\hline & Model 1 & Model 2 & Model 3 \\
\hline $\mathrm{R}^{2 *}$ & 0.9443 & 0.9793 & 0.9310 \\
\hline $\mathrm{RSD}^{* *}$ & $2.30 \%$ & $1.82 \%$ & $2.41 \%$ \\
\hline $\mathrm{MSR}^{* * *}$ & 0.0051 & 0.0021 & 0.0067 \\
\hline
\end{tabular}

$* \mathrm{R}^{2}=$ Determination coefficient, $* * \mathrm{RSD}=$ Relative standard deviator $* * * \mathrm{MSR}=$ Mean square error.

\subsection{Models Validation and Comparison}

The data used for the model validation are presented in Table 5 and the geotechnical properties of the soils for the validation data indicated that the soil sample is of high expansiveness. Two equations reported by $[40,41]$ were used for the validation of swelling stress, and equations are expressed in Eqs. 7, and 8a and b.

$$
\begin{gathered}
P_{s}=162.6 e^{0.0003 \psi} \text { Armand and Dzogbewu (2020) } \\
P_{s}=55+\beta_{c} \times \psi_{m}\left[\frac{s}{100}\right]^{2} \quad \text { Tu et al (2016) }
\end{gathered}
$$

$$
\beta_{c}=\left[\frac{0.25}{1000}\right] \times e^{5.306\left(\gamma_{d \max }\right)}
$$

However, Plastic index (P.I.), GMC, FSI, dry density, and suction are factors that govern the swelling behaviour of expansive soils, because they are determined from the physicochemical mechanism of the soil. These properties are largely a phenomenological and user-defined concept. Thus, the determination of these properties for identical expansive soil samples has been reported to produce reliable results with a mean square error of close to zero, though it is sensitive to the specimen preparation method. 
Table 5. Independent data used for model validation.

\begin{tabular}{|c|c|c|c|c|c|c|}
\hline Actual $P_{s}(k P a)$ & $\begin{array}{c}\text { Independent } P_{\mathrm{s}} \\
(\mathrm{kPa})\end{array}$ & $\begin{array}{c}\text { Model } 4 \\
(\mathrm{kPa})\end{array}$ & $\begin{array}{c}\text { Model 5 } \\
(\mathrm{kPa})\end{array}$ & $\begin{array}{c}\text { Model } 6 \\
(\mathrm{kPa})\end{array}$ & $\begin{array}{c}\text { Model } 7 \\
(\mathrm{kPa})\end{array}$ & $\begin{array}{c}\text { Model 8 } \\
(\mathrm{kPa}) \\
\end{array}$ \\
\hline 870 & 1000 & 761 & 829 & 816 & 1305 & 2082 \\
\hline 680 & 910 & 680 & 790 & 736 & 729 & 1522 \\
\hline 600 & 730 & 620 & 667 & 680 & 507 & 1136 \\
\hline 530 & 640 & 515 & 565 & 600 & 354 & 777 \\
\hline 460 & 520 & 490 & 480 & 500 & 214 & 276 \\
\hline 800 & 700 & 600 & 720 & 680 & 2093 & 2555 \\
\hline 680 & 560 & 550 & 600 & 590 & 1267 & 2052 \\
\hline 580 & 500 & 480 & 510 & 500 & 727 & 1496 \\
\hline 520 & 380 & 430 & 450 & 410 & 437 & 988 \\
\hline 350 & 210 & 300 & 320 & 320 & 264 & 483 \\
\hline 750 & 630 & 700 & 711 & 708 & 1142 & 1949 \\
\hline 700 & 580 & 610 & 691 & 689 & 761 & 1543 \\
\hline 600 & 510 & 570 & 530 & 613 & 582 & 1274 \\
\hline 460 & 460 & 480 & 500 & 522 & 388 & 869 \\
\hline 400 & 400 & 412 & 400 & 348 & 222 & 312 \\
\hline 800 & 899 & 737 & 800 & 794 & 1157 & 1962 \\
\hline 719 & 749 & 680 & 750 & 790 & 977 & 1792 \\
\hline 600 & 630 & 600 & 600 & 650 & 664 & 1406 \\
\hline 450 & 450 & 516 & 480 & 500 & 376 & 837 \\
\hline 380 & 300 & 417 & 350 & 413 & 228 & 336 \\
\hline 830 & 900 & 780 & 850 & 800 & 2164 & 2588 \\
\hline 725 & 825 & 700 & 802 & 788 & 1233 & 2026 \\
\hline 680 & 750 & 670 & 755 & 740 & 954 & 1769 \\
\hline 520 & 620 & 522 & 580 & 534 & 388 & 868 \\
\hline 400 & 500 & 480 & 462 & 480 & 248 & 423 \\
\hline 780 & 655 & 729 & 684 & 650 & 1108 & 1919 \\
\hline 650 & 567 & 560 & 631 & 600 & 808 & 1603 \\
\hline 521 & 521 & 510 & 510 & 521 & 458 & 1035 \\
\hline 480 & 400 & 400 & 410 & 408 & 296 & 599 \\
\hline 350 & 217 & 290 & 280 & 318 & 236 & 372 \\
\hline 810 & 910 & 780 & 800 & 820 & 2104 & 2560 \\
\hline 710 & 818 & 700 & 754 & 728 & 1013 & 1829 \\
\hline 630 & 776 & 685 & 704 & 655 & 655 & 1392 \\
\hline 500 & 627 & 477 & 600 & 456 & 308 & 640 \\
\hline 420 & 491 & 491 & 480 & 480 & 246 & 413 \\
\hline
\end{tabular}


Table 5 Continued

\begin{tabular}{|c|c|c|c|c|c|c|}
\hline 730 & 992 & 662 & 850 & 800 & 792 & 1583 \\
\hline 620 & 870 & 614 & 671 & 790 & 621 & 1339 \\
\hline 610 & 750 & 533 & 595 & 730 & 411 & 927 \\
\hline 550 & 604 & 504 & 536 & 539 & 355 & 779 \\
\hline 458 & 458 & 415 & 393 & 440 & 226 & 327 \\
\hline 800 & 969 & 728 & 900 & 835 & 1107 & 1918 \\
\hline 720 & 872 & 618 & 800 & 747 & 632 & 1357 \\
\hline 600 & 762 & 554 & 700 & 674 & 434 & 981 \\
\hline 530 & 589 & 470 & 565 & 571 & 297 & 603 \\
\hline 420 & 420 & 438 & 450 & 480 & 253 & 444 \\
\hline 790 & 788 & 700 & 720 & 785 & 1356 & 2121 \\
\hline 620 & 558 & 580 & 550 & 590 & 950 & 1765 \\
\hline 580 & 485 & 500 & 480 & 500 & 533 & 1187 \\
\hline 440 & 400 & 450 & 430 & 420 & 313 & 654 \\
\hline 400 & 386 & 410 & 400 & 400 & 228 & 338 \\
\hline 664 & 750 & 603 & 561 & 576 & 584 & 1278 \\
\hline 600 & 685 & 586 & 570 & 585 & 538 & 1196 \\
\hline 578 & 610 & 523 & 525 & 540 & 390 & 583 \\
\hline 480 & 560 & 471 & 445 & 460 & 299 & 608 \\
\hline 350 & 480 & 408 & 460 & 500 & 199 & 200 \\
\hline 700 & 680 & 607 & 607 & 620 & 596 & 1299 \\
\hline 670 & 607 & 570 & 580 & 593 & 495 & 1112 \\
\hline 560 & 553 & 511 & 540 & 541 & 366 & 812 \\
\hline 460 & 460 & 452 & 455 & 467 & 272 & 514 \\
\hline 400 & 260 & 396 & 310 & 387 & 204 & 228 \\
\hline
\end{tabular}

The validation of the developed swelling stress models using independent data set is presented in Figs. 7 through 9. The equations were compared with a randomly selected swelling stress equation as presented in equations from Table 4. The graphical illustration of the scatter plot followed the trend of a 1:1 line for the models. 4, 5, and 6 were developed by the Authors. This implies that the predicted values portrayed a good correlation concerning the independent values, with negligible disparities as presented in the curve. The Author's model 4 rendered the highest $\mathrm{R}^{2}$ magnitudes corresponding to $\mathrm{R}^{2}$ values of 0.858 , the predictive equation is based on suction. Models 5 and 6 recorded the second-highest $\mathrm{R}^{2}$ values of 0.931 and 0.890 , respectively. It is noted that the model with only dry unit weight, FSI, and suction closely predicted the swelling stress values of unsaturated expansive soils due to the strong affinity of these soils with moisture and suction. It is also noted that for highly clayey unsaturated expansive soils, swelling is dependent on electrical, chemical, and physical forces that act on the surface of clay platelets. This surface force attraction is related to the interaction between the suction and moistures with capillary force. Furthermore, the hydromechanical properties of suction which reflect how the soil particles are bonded together by tension surface force as well as the structure of the clay minerals rendered a good fit of proportionalities between the suction and other soil properties. 

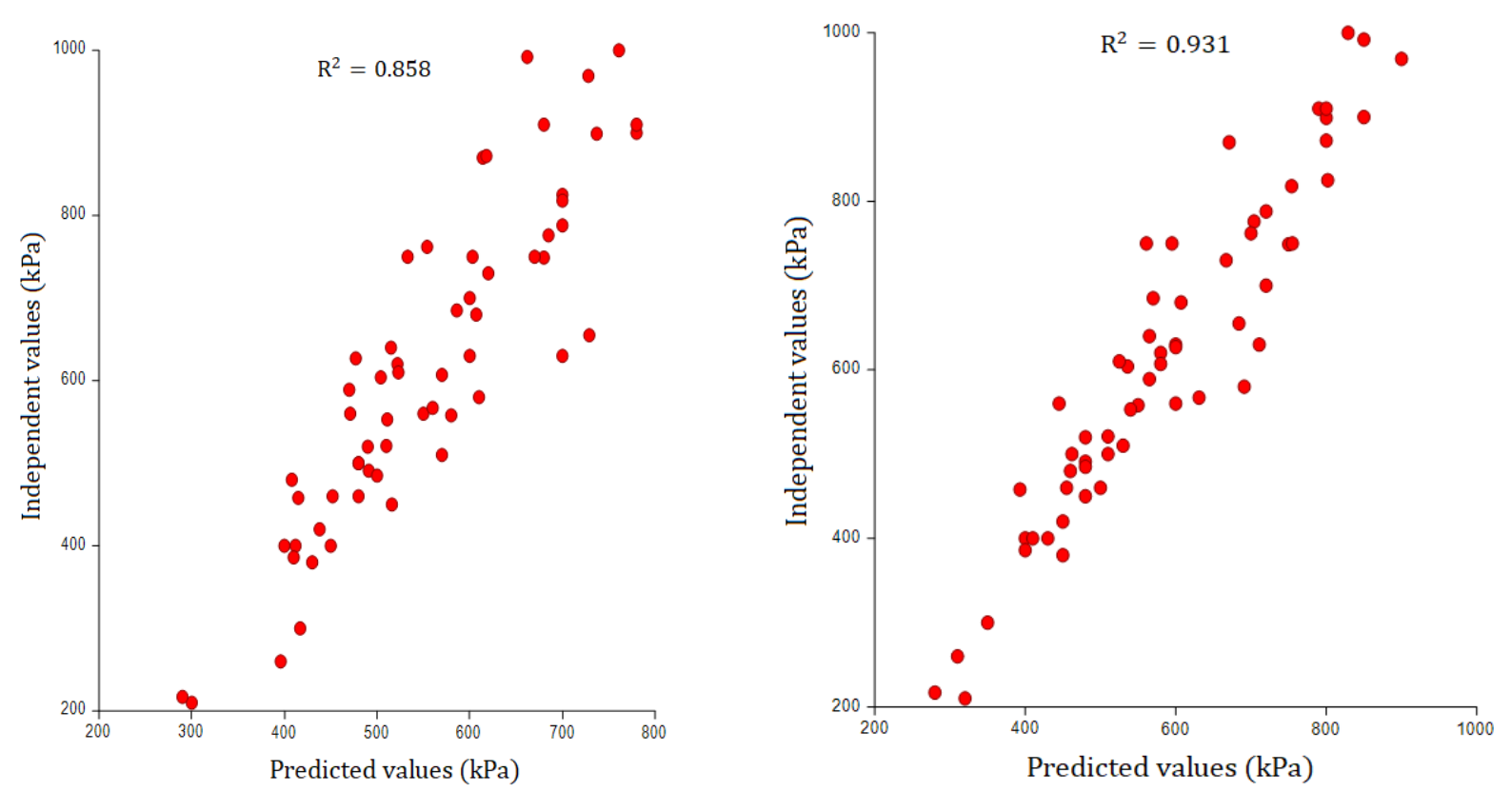

Figure 7. Validation of the developed swelling stress for models 4 and 5

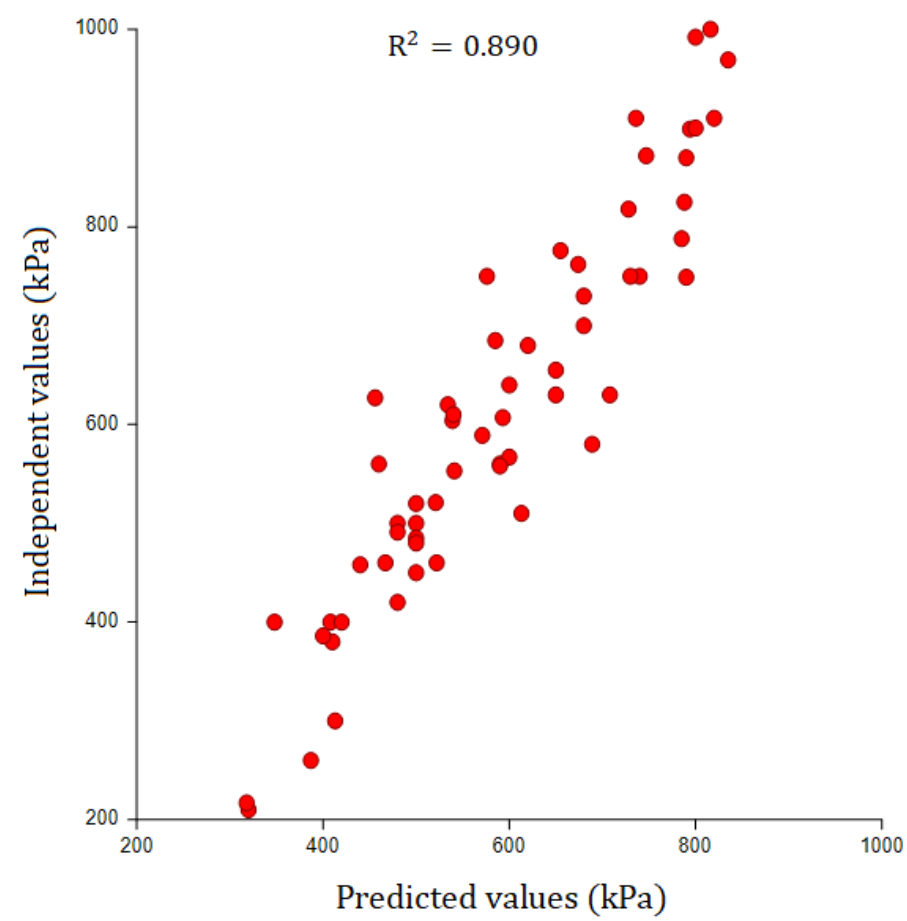

Figure 8. Validation of the developed swelling stress for model 6 

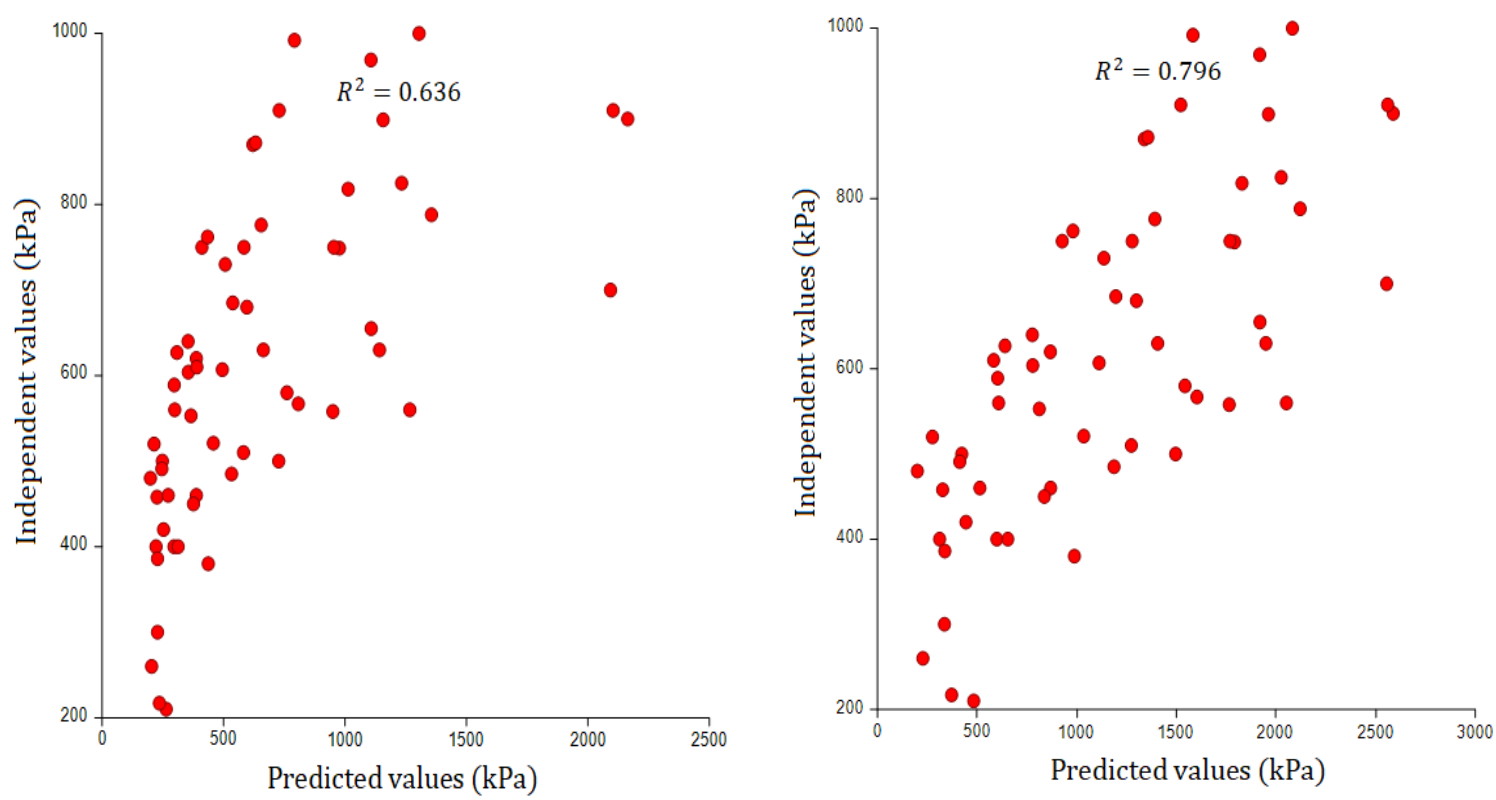

Figure 9. Validation of the developed swelling stress for models 7 and 8

Table 6. Models summary

\begin{tabular}{|c|c|c|c|c|c|}
\hline Models & $\mathbf{R}^{\mathbf{2}}$ & Adj $\mathbf{R}^{\mathbf{2}}$ & Ave. Abs \% Error & Square Root of MSE & Comments \\
\hline 4 & 0.858 & 0.8555 & 11.115 & 70.42857 & Good fit \\
\hline 5 & 0.931 & 0.9296 & 7.819 & 49.43072 & Strongly predicted \\
\hline 6 & 0.890 & 0.8877 & 9.853 & 60.52818 & Good fit \\
\hline 7 & 0.636 & 0.6293 & 22.952 & 114.3371 & Marginal \\
\hline 8 & 0.796 & 0.7928 & 21.309 & 88.62538 & Averagely predicted \\
\hline
\end{tabular}

Based on the independent data presented in this research, a comparison was conducted between the Authors and other models. It was observed that model 5 developed by the Authors rendered a very close approximation compared to the models by $[40,41]$ which overestimated swelling stress. Generally, the summary performance of all the validated models is presented in Table 6 . it is observed that the equations used for the prediction in this study provided a reliable degree of accuracy in the prediction of swelling stress based on the $\mathrm{R}^{2}$ values. Contrary to other predictive models, Tu et al [41] equation rendered $R^{2}$ values of 0.796 , this implies that the equation has low correlation capability compared to the models developed in this study.

\section{SEM}

SEM test was used to examine the morphological features of the investigated soils. EDS was also employed to aid the identification of chemicals and dominant phases through the elemental micrograph. Figs 10 through 14 illustrate the SEM micrographs of average soils from the five visited sites. The soil is comprised mainly of quartz grains interspersed with sparsely present smectite, silica, $\mathrm{K}$-feldspar, plagioclase, illite, and calcite as the dominant clay minerals. Also, the structure of soils has dispersed fabric in a natural state as presented and consists mainly of flaky-like texture particles. This confirmed the high values of swelling stress as reported earlier in this study. The surface morphology of soils seems plain with content precursors of quartz, kaolinite, and hematite precipitates within micropore spaces at trace level. The formation of a flocculated soil structure is highlighted on the micrographs; the presence of a tetrahedral layer could be seen on the surface of each micrograph. The micrograph of the soils has a smooth surface in which the hydroxyls rendered a tetrahedron-enclosed silicon atom. The tetrahedron layer is combined in a sheet-like structure with a common plane. 


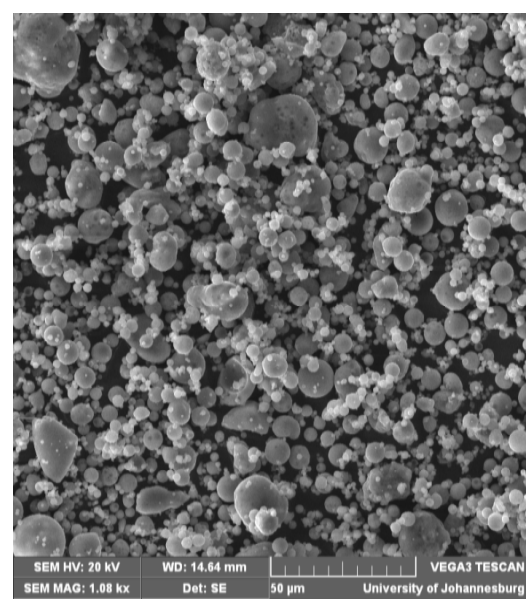

(a)

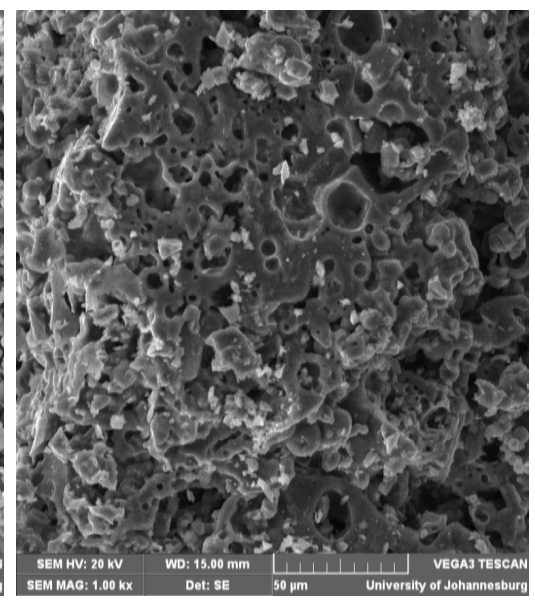

(b)

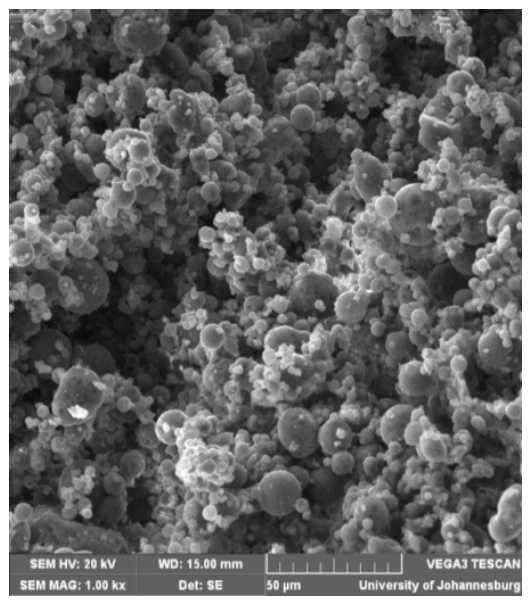

(c)

Figure 10. SEM of site 1, Soils A, B, and C

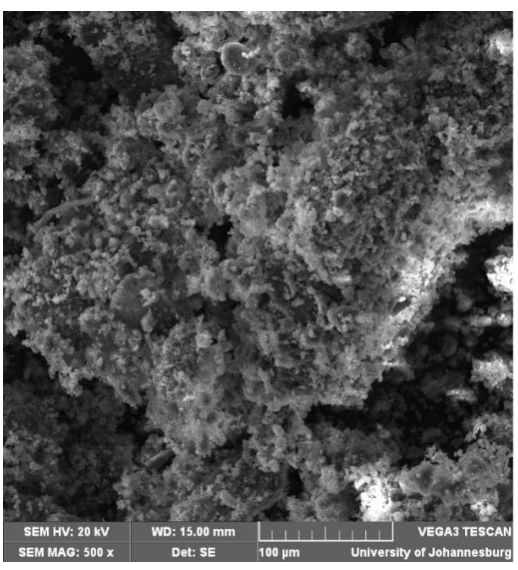

(a)

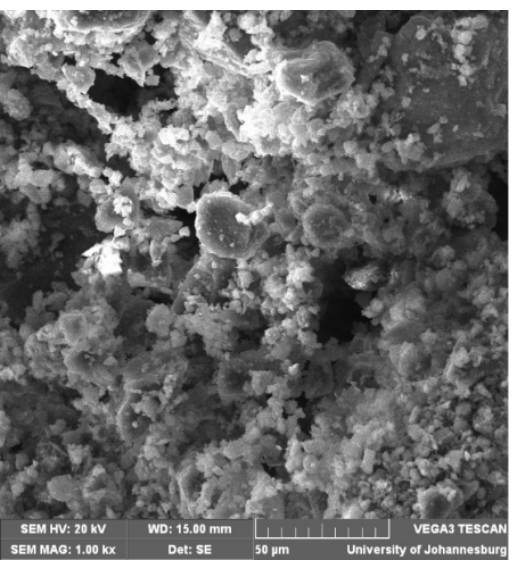

(b)

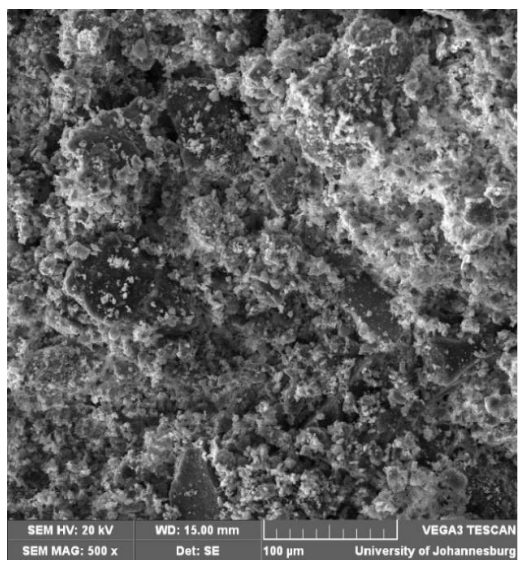

(c)

Figure 11. SEM of site 2, Soils A, B, and C

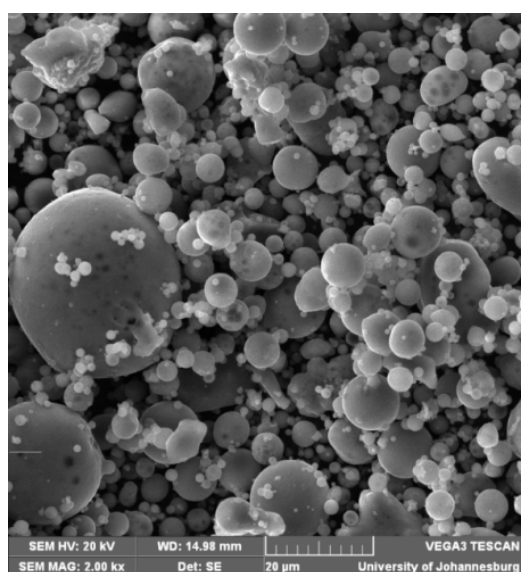

(a)

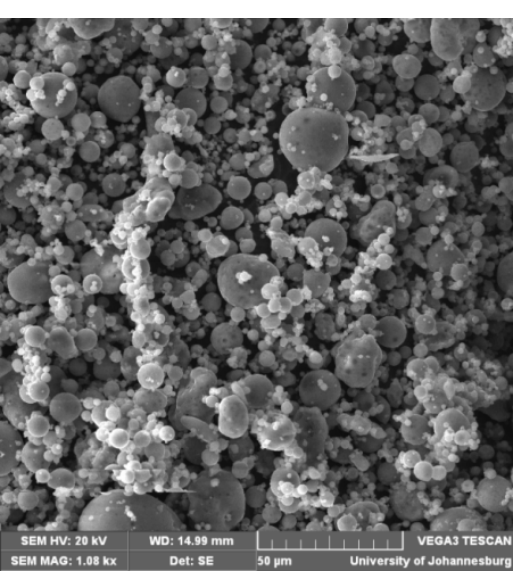

(b)

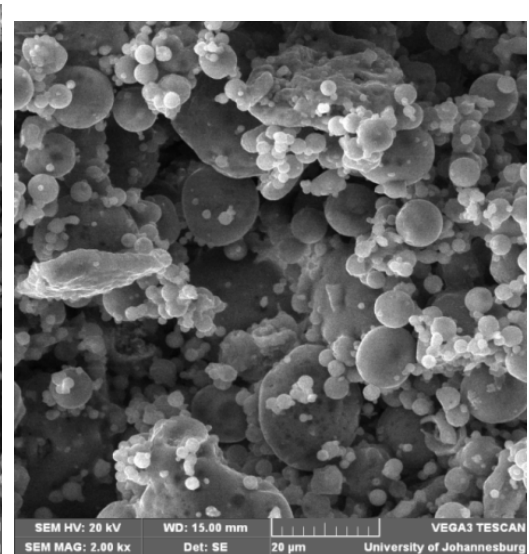

(c)

Figure 12. SEM of site 3, Soils A, B, and C 


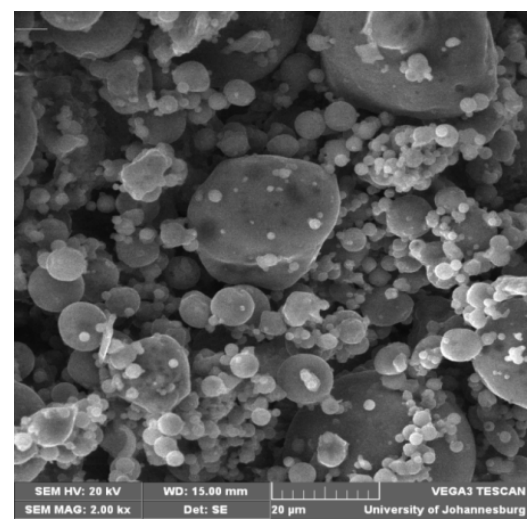

(a)

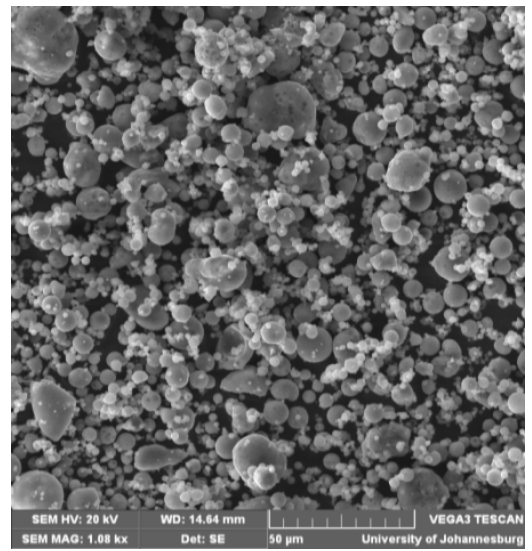

(a)

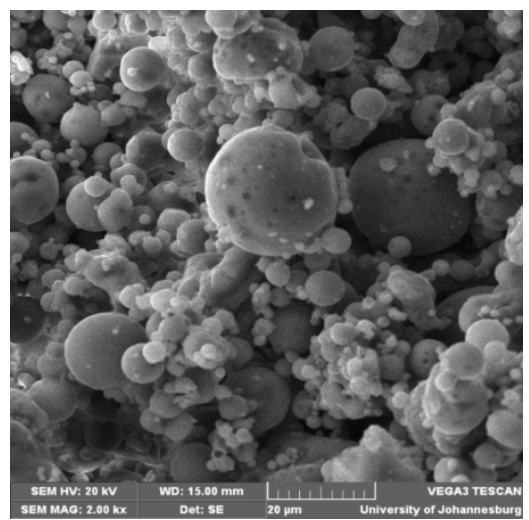

(b)

Figure 13. SEM of site 4, Soils A, B, and C

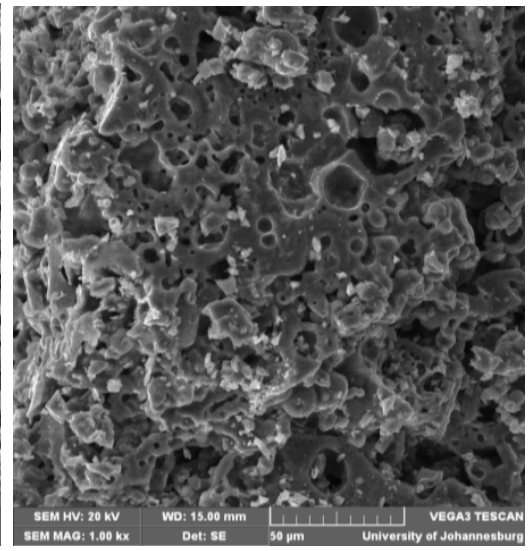

(b)

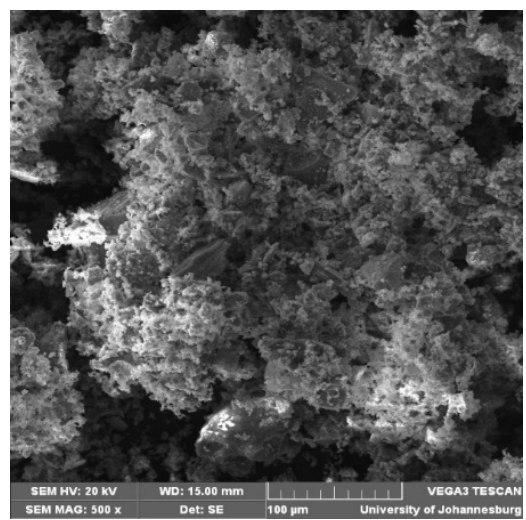

(c)

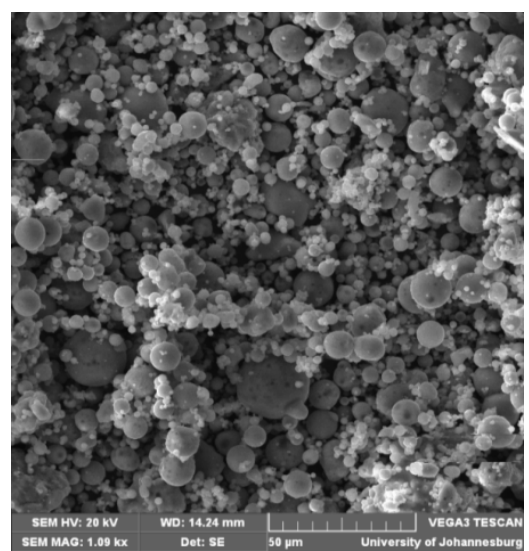

(c)

Figure 14. SEM of site 5, Soils A, B, and C

\section{Conclusions}

In this study, assessment of swelling stress predictive models for compacted unsaturated expansive soils was investigated using models developed by the authors and models randomly selected from the literature. The models were validated using independent data set, based on the obtained validation curves, it was concluded that.

The performance level attained by the author's developed models implies that the three models could be used as a tool to minimize the uncertainties encountered in soil engineering projects with a high degree of accuracy.

Overall, the validity of the developed equations was checked using independent data, the check revealed a high level of coefficient of correlation compared to the selected models from the literature. The study clearly shows that the independent swelling stress data showed good agreement with the estimated values from the developed equations.

SEM analysis revealed that the soils are expansive, as confirmed by their corresponding values of micrographs analysis revealing, smectite, silica, K-feldspar, plagioclase, illite, and calcite as the dominant clay minerals.
The correlation of swelling stress with suction and gravimetric moisture content greatly influences the swelling stress values as it allowed for the development of a predictive equation with corresponding $\mathrm{R}^{2}$ value of 0.9045 and 0.9235 respectively. The independent data proved that the developed models are reliable for predicting the swelling stress of compacted unsaturated expansive soils at high suction.

The plotted data points are close to the 1:1-line, standard deviator $<3 \%$, mean squared errors for the developed models are approximately zero, the determination coefficient $\mathrm{R}^{2}$ is greater than $>0.8$. Graphical comparisons demonstrate a better correlation between the proposed models. These models could be reliably used as a tool to predict the swelling stress with allowable accuracy.

\section{Acknowledgments}

The authors would like to acknowledge the Geotechnical and Geoenvironmental research group at the University of Kwazulu-Natal Durban, South Africa. 


\section{Declaration}

No potential conflict of interest was reported by the authors.

\section{REFERENCES}

[1] Aneke Frank Ikechukwu, Mostafa Mohamed Hassan, Azza Moubarak, "Behaviour of Unsaturated Soils for Road Pavement Structure under Cyclic Loading," $\mathrm{PhD}$ Thesis in Civil Engineering, 2018. Central University of Technology Free State. http://hdl.handle.net/11462/2028.

[2] Adel Djellali, Abdelhafid Ounis., Behrooz Saghafi, "Behaviour of flexible pavements on expansive soils," Int. J. of Transp. Eng., Vol.1, No. 1, pp. 1-14, 2012. DOI: 10.22119/IJTE.2013.2626.

[3] Hana H. Adem, Vanapalli K. Sai, "Constitutive modelling approach for estimating1-Dheave with respect to time for expansive soils," International Journal of Geotechnical Engineering, Vol. 7, No. 2, pp. 199-204, 2013. https://doi.org/10.1179/1938636213Z.00000000024.

[4] Diop Souleymane., Stapelberg Frederik, Tegegn Kefyalew, Ngubelanga Sifiso, Heath Lindy, "A review of problem soils in South Africa," Council for Geoscience Report Number: 2011-0062.

[5] Mahmoud A. Mahrous, Šegvić Branimir, Zanoni Giovanni, Suraj D. Khadka, Senadheera Sanjaya, Priyantha W. Jayawickrama, "The Role of Clay Swelling and Mineral Neoformation in the Stabilization of High Plasticity Soils Treated with the Fly Ash- and Metakaolin-Based Geopolymers," Minerals. Vol. 8, no. 4, pp.146. 2018 https://doi.org/10.3390/min8040146.

[6] Gökalp Zeki., Başaran Mustafa., Oğuzhan Uzun, "Compaction and swelling characteristics of sandbentonite and pumice-bentonite mixtures," Clay Miner. Vol. 46, No. 3, pp. 449-459. 2011 doi:10.1180/claymin.2011.046.3.449.

[7] Erzin Yusuf, Erol Orhan, "Correlations for quick prediction of swell pressures. The Electronic Journal of Geotechnical Engineering, 9(F), 0476 (2004). Available from http://www.ejge.com/2004/Ppr0476/Ppr0476.htm.

[8] Zeynal Abiddin Erguler, Resat Ulusay, “A simple test and predictive models for assessing swell potential of Ankara (Turkey) Clay," Engineering Geology, Vol. 67, No. 3, pp.331-352. 2003

https://doi.org/10.1016/S0013-7952(02)00205-3.

[9] Phanikumar B.R., Dembla Supriya, Yatindra, A. Swelling Behaviour of an Expansive Clay Blended with Fine Sand and Fly Ash. Geotech Geol Eng. Vol.39, pp.583-591. 2021. https://doi.org/10.1007/s10706-020-01480-6.

[10] Kayabali Kamil, Demir Saniye, Measurement of swelling pressure: direct method versus indirect methods. Canadian Geotechnical Journal, Vol. 48, No. 3, pp. 354-364. 2001. DOI: $10.1139 / \mathrm{T} 10-074$

[11] Çimen Ömür., Nilay s. Keskin, Hüseyin Yıldırım,
"Prediction of swelling potential and pressure in compacted clay," Arabian Journal of Science and Engineering, Vol. 37 No. 6, pp 1535-1546. 2012 https://doi.org/10.1007/s13369-012-0268-4

[12] Vanapalli K. Sai, Lu Lu, "A state-of-the art review of 1-D heave prediction methods for expansive soils," International Journal of Geotechnical Engineering, Vol. 6 No. 1, pp 15-4, 2012. DOI:10.3328/IJGE.2012.06.01.15-4 1.

[13] Vanapalli K Sai, Won Oh, "A model for predicting the modulus of elasticity of unsaturated soils using the soil-water characteristic curve." International Journal of Geotechnical Engineering, Vol. 4, No. 4, pp 425-433. 2010 https://doi.org/10.3328/IJGE.2010.04.04.425-433.

[14] Aravind Pedarla, Anand J. Puppala, Laureano R. Hoyos, Sai K. Vanapalli, Claudia Zapata, "SWRC Modelling Framework for Evaluating Volume Change Behaviour of Expansive Soils," In: Mancuso C., Jommi C., D’Onza F. (eds) Unsaturated Soils: Research and Applications. Springer, Berlin, Heidelberg. https://doi.org/10.1007/978-3-642-31116-1_30.

[15] Setianto Samingan Agus., Tom Schanz, "A method for predicting swelling pressure of compacted bentonites," Acta Geotech. Vol.3, Article number 125. 2008. https://doi.org/10.1007/s11440-008-0057-0.

[16] Erzin, Yusuf., Orhan Erol, "Swell pressure prediction by suction methods," Engineering Geology, Vol. 92, No. 3, pp. 133-145. 2007. DOI: 10.1016/j.enggeo.2007.04.002.

[17] Victor Cantillo, Vicente Mercado, César Pájaro, "Empirical Correlations for the Swelling Pressure of Expansive Clays in the City of Barranquilla," Colombia Earth Sciences Research Journal, vol. 21, no.1, pp. 45-49, 2017. DOI: 10.15446/esrj. v21n1.60226.

[18] Dorota Izdebska-Mucha, Emilia Wojcik, "Evaluation of expansivity of Neogene clays and glacial tills from central Poland on the basis of suction tests. Geological Quarterly, Vol. 59, No. 3, pp.593-602, 2015, DOI: 10.7306/gq.1233

[19] ASTM, "Standard Test Method for Particle-size Distribution (Gradation) of Fine-Grained Soils Using the Sedimentation (Hydrometer) Analysis," D 7928; 04. 09, American Society for Testing and Materials, PA, USA, 2016. DOI: $10.1520 / \mathrm{d} 7928-16 \mathrm{e} 01$.

[20] Francisco Lamas, Irigaray, C., José Chacón “Geotechnical characterization of carbonate marls for the construction of impermeable dam cores," Eng. Geol. 66, 283-294. 2002. doi:10.1016/ S0013-7952(02)00048-0.

[21] ASTM, "Standard Test Methods for Laboratory Compaction Characteristics of Soil Using Standard Effort (12 $\left.400 \mathrm{ft}-\mathrm{lbf} / \mathrm{ft}^{3}\left(600 \mathrm{kN}-\mathrm{m} / \mathrm{m}^{3}\right)\right)$," ASTM International, West Conshohocken, PA, 2012, https://dx.doi.org/10.1520/D0698-12E02.

[22] IS, Part XL.: Method of Test for Soils Part XL Determination of Free Swell Index of Soils." Bureau of Indian Standards, 2720, Part XL. 2002. https://law.resource.org/pub/in/bis/S03/is.2720.1.1983.

[23] ASTM, "Standard Test Method for Measurement of Soil potential (Suction) using filter paper," D 5298; 04. 08, American Society for Testing and Materials, PA, USA, 
2016. DOI: $10.1520 / \mathrm{d} 5298-16$.

[24] Rifat Bulut, Eng Choon Leong, Indirect Measurement of Suction. In: Tarantino A., Romero E., Cui YJ. (eds) Laboratory and Field Testing of Unsaturated Soils. Springer, Dordrecht. 2008

https://doi.org/10.1007/978-1-4020-8819-3_3.

[25] I.S Part. 1., "Method of Test for Soils Part 41 Determination of Soil Swelling Stress," Bureau of Indian $\begin{array}{llll}\text { Standards } & 2720 . & \text { Part } & 40 .\end{array}$ https://law.resource.org/pub/in/bis/S03/is.2720.1.1983.pdf.

[26] Abdullah I. Al-Mhaidib, Mosleh A. Al-Shamrani, "Influence of Swell on Shear Strength of Expansive Soils. Advances in Unsaturated Soil, Seepage, and Environmental Geotechnics, 16 160-165. 2006. DOI: 10.1061/40860(192)16.

[27] Yugantha Y. Perera, Claudia Zapata, William N. Houston, Sandra Houston, "Long-Term Moisture Conditions under Highway Pavements," Proceeding of Geo-Trans 2004, Geotechnical Special Publication No. 126, Geotechnical Engineering for Transportation Projects. ASCE Geo-institute. Los Angeles, CA, Vol. 1, pp. 1132-1143. July 27-31. http://worldcat.org/isbn/0784407444.

[28] Botao Lin, Amy Cerato, "Prediction of expansive soil swelling based on four micro-scale properties" Eng Geol Environ, No. 71:71-78. 2012. DOI:10.1007/s10064-011-0410-7.

[29] Satoru Suzuki, Somchai Prayongphan, Yasuaki Ichikawa, Byung-Gon Chae, "In situ observations of the swelling of bentonite aggregates in $\mathrm{NaCl}$ solution. Appl. Clay Sci. 2005, Vol. 29, pp. 89-98. DOI: 10.1016/j.clay.2004.11.001.

[30] Frank Ikechukwu Aneke, Mohamed M.H. Mostafa, Walid El Kamash, Pre-compression, and capillarity effect of treated expansive subgrade subjected to compressive and tensile loadings, Case Studies in Construction Materials, Volume 15, 2021, e00575, ISSN 2214-5095, https://doi.org/10.1016/j.cscm.2021.e00575.

[31] Haibo Lyu, Jianxiao Gu, Wenjie Li, Fabiao Liu "Analysis of compressibility and mechanical behaviour of red clay considering structural strength. Arab J Geosci Vol. 13, pp. 411. 2020. https://doi.org/10.1007/s12517-020-05352-4

[32] Changxi Huang, Xinghua Wang, Hao Zhou, Yan Liang, "Factors Affecting the Swelling-Compression Characteristics of Clays in Yichang, China", Advances in
Civil Engineering, vol. 2019, Article ID 6568208, 13 pages, 2019. https://doi.org/10.1155/2019/6568208.

[33] Zhong Han, Sai K. Vanapalli "Semiempirical model for predicting the resilient modulus of unsaturated fine-grained soils;' Proc. of the 6th International Conference on Unsaturated Soils, July 2014, Sydney, Australia. DOI: 10.1201/b17034-113.

[34] Aneke Frank Ikechukwu, Mostafa Mohamed Hassan, and Azza Moubarak, "Swelling stress effects on shear strength resistance of subgrades," International Journal of Geotechnical Engineering 201. DOI: $10.1080 / 19386362.2019 .1656445$.

[35] Aneke Frank Ikechukwu, Mostafa Mohamed Hassan, Azza Moubarak, "Characterization of hydromechanical effects of suction and clay minerals on resilient modulus," GeoMEast 2018 International Congress and Exhibition. ISSMGE; Cairo, Egypt, Egypt. DOI: 10.1080/19386362.2019.1656919.

[36] Young-Suk Song, Seongwon Hong, "Effect of clay minerals on the suction stress of unsaturated soils," Engineering Geology, Vol. 269, 105571, ISSN 0013-7952, $2020 \mathrm{https} / / /$ doi.org/10.1016/j.enggeo.2020.105571.

[37] Yusuf Erzin, Nazmi Günes,, "The unique relationship between swell percent and swell pressure of compacted clays," Bulletin of Engineering Geology and the Environment, vol. 72, (2013) no. 1, pp. 71-80. https://doi.org/10.1007/s10064-013-0461-z.

[38] Mohammed Y. Fattah, Aysar H.S. Al-Lami, "Behaviour and characteristics of compacted expansive unsaturated bentonite-sand mixture, Journal of Rock Mechanics and Geotechnical Engineering, Vol. 8, Issue 5, 2016, Pages 629-639, ISSN 1674-7755, https://doi.org/10.1016/j.jrmge.2016.02.005.

[39] Armand A. Fondjo, Thywill C. Dzogbewu, "Swelling Stress and Suction Correlation of Compacted, Heaving Soils," Civil Engineering and Architecture, Vol. 8, No. 4, pp. 721 733, 2020. DOI: 10.13189/cea.2020.080434.

[40] Hongyu Tu, Sai K. Vanapalli, "Prediction of the Variation of Swelling Pressure and One-Dimensional Heave of Expansive Soils with Respect to Suction Using the Soil-Water Retention Curve as a Tool," Canadian Geotechnical Journal, vol. 53, no 8, pp. 1213-1234, 2016, DOI: $10.1139 /$ cgj-2015-0222. 